\title{
A Numerical Case Study of Secondary Marine Cyclogenesis Sensitivity to Initial Error and Varying Physical Processes
}

\author{
Marco L. Carrera, John R. Gyakum, and Da-Lin Zhang* \\ Department of Atmospheric and Oceanic Sciences, McGill University, Montreal, Quebec, Canada
}

(Manuscript received 3 November 1997, in final form 1 June 1998)

\begin{abstract}
Secondary cyclogenesis has been identified as a difficult forecast challenge. In this paper, the authors examine the dominant physical processes associated with the predictability of a case of explosive secondary marine cyclogenesis and provide a better understanding of the large variability in the recent model-intercomparison simulations of the case. A series of sensitivity experiments, involving changes to the model initial conditions and physical parameterizations, is performed using the Canadian Mesoscale Compressible Community Model with a grid size of $50 \mathrm{~km}$.

It is found that errors in the model initial conditions tend to decay with time, and more rapidly so in "dry" simulations. The model fails to produce the secondary cyclogenesis in the absence of latent heating. Water vapor budget calculations from the control experiment show that the surface moisture flux from 6 to $12 \mathrm{~h}$ is the largest contributor of water vapor to the budget area in the vicinity of the cyclone center, and remains an important moisture supply throughout the integration period. During the first $12 \mathrm{~h}$, these fluxes are crucial in inducing grid-scale diabatic heating and destabilizing the lower troposphere, thereby facilitating the subsequent rapid deepening of the storm. A secondary maximum in surface latent heat flux to the north and east of the primary maximum acts to force the cyclogenesis event to the south and east of a coastal circulation center. When the surface evaporation is not allowed, much less precipitation is produced and the secondary cyclone fails to develop. Calculations of the potential temperature on the dynamic tropopause (i.e., 2-PVU surface) in the absence of surface evaporation indicate a significantly damped thermal wave when compared with the control integration.

This result for a case of secondary cyclogenesis differs from those generally found for large-scale extratropical cyclogenesis where upper-level baroclinic forcings tend to dominate, and motivates the need for better physical parameterizations, including the condensation and boundary layer processes, in operational models. The authors speculate that the different treatment of condensation and boundary layer processes may have been partly responsible for the enhanced variability in the simulation of this case in a recently completed international mesoscale model intercomparison experiment.
\end{abstract}

\section{Introduction}

Along the east coast of North America, a special type of cyclogenesis occurs frequently during the cold season (Miller 1946). Typically, a large-scale (mature) low pressure system (i.e., a primary cyclone) propagates slowly northeastward from the Great Lakes region. Cold air surges over the warmer waters of the Gulf Stream to the southeast of the primary low, acting to destabilize the lower troposphere, while strong warm advection to the north and east produces a significant low-level baroclinic zone along the coast. In this region, a secondary

\footnotetext{
* Current affiliation: Department of Meteorology, University of Maryland at College Park, College Park, Maryland.

Corresponding author address: Mr. Marco L. Carrera, Department of Atmospheric and Oceanic Sciences, McGill University, 805 Sherbrooke St. West, Montreal, PQ H3A 2K6, Canada.

E-mail: marco@zephyr.meteo.mcgill.ca
}

cyclone, with a diameter of 500-1500 km, often forms in the wake of the preexisting primary cyclonic circulation. This type of cyclogenesis has been identified as a difficult forecast challenge (Kuo et al. 1995; Snyder 1996). This has motivated the meteorological community to conduct the Fronts and Atlantic Storm-Track Experiment (Snyder 1996; Joly et al. 1997). Linked with this forecast challenge was a need to clarify the role of upper- and lower-tropospheric processes in triggering the secondary cyclogenesis.

Recently, an international mesoscale model intercomparison effort known as COMPARE (Comparison of Mesoscale Prediction and Research Experiments; Gyakum et al. 1995) was undertaken to understand further the predictive capability of numerical weather prediction models on marine cyclones. One of its long-term objectives is to choose cases of meso- $\alpha$-scale phenomena from high-resolution field experiments and to perform model intercomparison experiments in an effort to identify systematic modeling errors (Chouinard et al. 1994). The first case chosen for COMPARE was an 
(a)

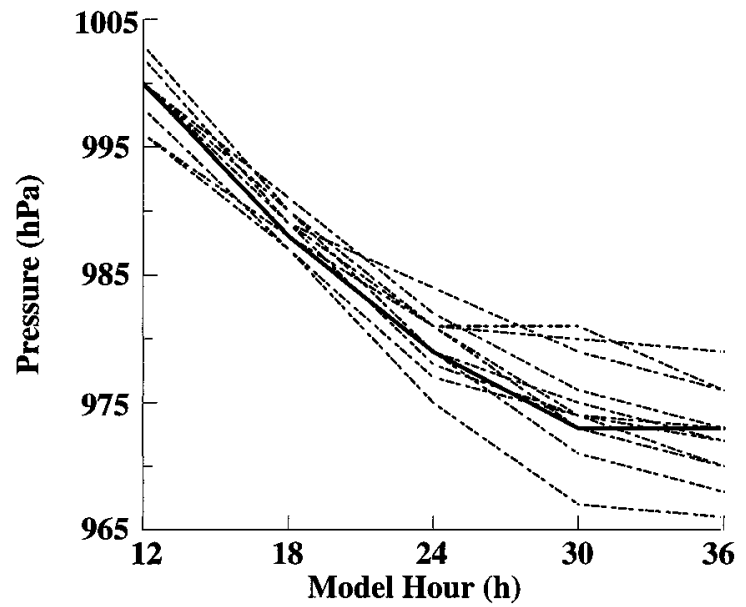

(b)

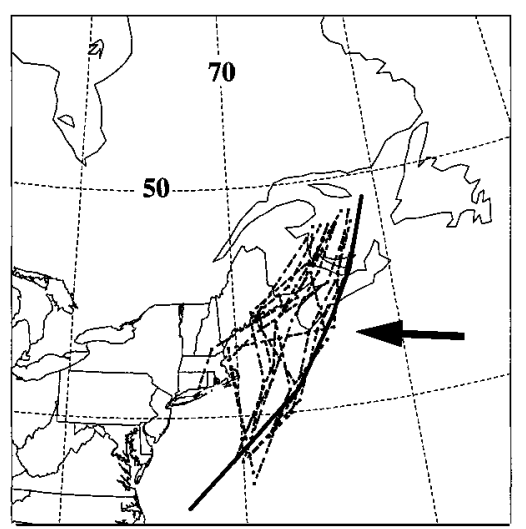

FIG. 1. (a) Traces of central SLP for the IOP-14 storm from COMPARE models (dashed). (b) Six-hourly cyclone positions starting from 0000 UTC 7 March 1986. For both (a) and (b) the RPN-prepared analyses is given in thick solid lines. Arrow in (b) points to cyclone positions at $24 \mathrm{~h}$. Latitude-longitude lines in (b) are shown each $10^{\circ}$.

explosive marine cyclone off the North American east coast that occurred between 6 and 9 March 1986 during the concurrent field programs of the Canadian Atlantic Storms Program (CASP; Stewart et al. 1987) and the Genesis of Atlantic Lows Experiment (GALE; Dirks et al. 1988). Because of its development during the 14th intense observing period (IOP) of CASP, we term this storm as the IOP-14 storm. Twelve state-of-the-art limited-area models from seven countries performed 36-h simulations. For a detailed description of the various models, see Gyakum et al. (1996).

Figure 1 compares the simulated central sea level pressure (SLP) traces and 6-hourly positions by the COMPARE models as verified against the observed event. The range of 12-h simulated central SLP values is about 7-8 hPa, which increases to $15 \mathrm{hPa}$ at the end of the 36-h simulation (Fig. 1a). The 6-h positions of the low center exhibit a bifurcation of the tracks after $18 \mathrm{~h}$, with several models tracking the system too far westward and inland; they recover thereafter to a more accurate position at $36 \mathrm{~h}$ (Fig. 1b). The largest vari-

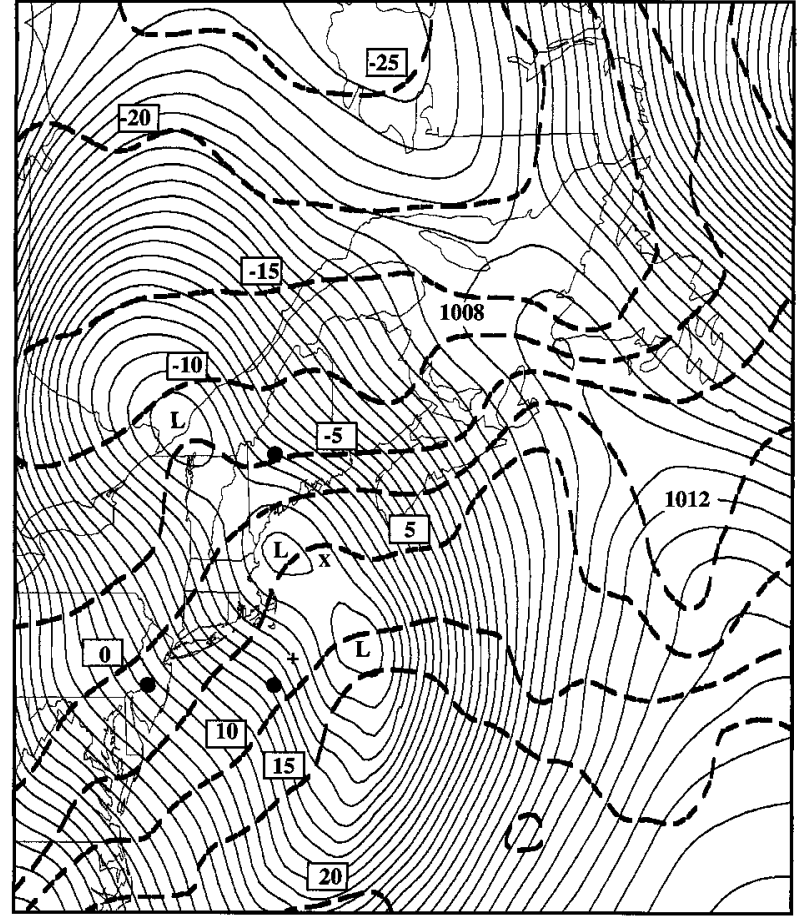

FIG. 2. RPN-prepared analyses SLP (solid) at intervals of $1 \mathrm{hPa}$ and surface temperature (dashed) at intervals of $5^{\circ} \mathrm{C}$ for $0600 \mathrm{UTC}$ 7 March 1986. The location of two buoys, 44005 and 44008, are given by $\times$ and + , respectively. Solid circles denote $45^{\circ} \mathrm{N}, 70^{\circ} \mathrm{W}$; $40^{\circ} \mathrm{N}, 70^{\circ} \mathrm{W}$; and $40^{\circ} \mathrm{N}, 75^{\circ} \mathrm{W}$

ability in cyclone positions occurs near $24 \mathrm{~h}$, as indicated by the arrow in Fig. $1 b$.

The bifurcation in cyclone tracks can be attributed partly to the lack of high-resolution observations to resolve three analyzed surface mesocyclones, as shown in Fig. 2 by the Recherche en Prévision Numérique (RPN) prepared SLP analysis. A time series of SLP and surface winds from two buoys, $44005\left(42.7^{\circ} \mathrm{N}, 68.3^{\circ} \mathrm{W}\right)$ and $44008\left(40.5^{\circ} \mathrm{N}, 69.5^{\circ} \mathrm{W}\right.$ ) (see Fig. 2), supports the existence of three mesocyclones in the analysis at 0600 UTC 7 March 1986. In fact, none of the COMPARE models was able to reproduce the three circulation centers (as shown in Fig. 2) at either 50- or 25-km horizontal resolution. All the COMPARE models reproduced the continental low; however, most of the models produced only the southeastern center offshore, missing the coastal circulation. A few models missed the offshore center altogether, producing only a circulation center along the coast. An examination of the detailed surface SLP analysis reveals that the IOP-14 storm was associated with the southeastern circulation center within the surface trough. Some of the COMPARE models producing the significant westward bias were found to deepen preferentially the middle circulation center along the New England coast, while those models possessing a more accurate track deepened the southeasternmost center within the trough after $18 \mathrm{~h}$. 

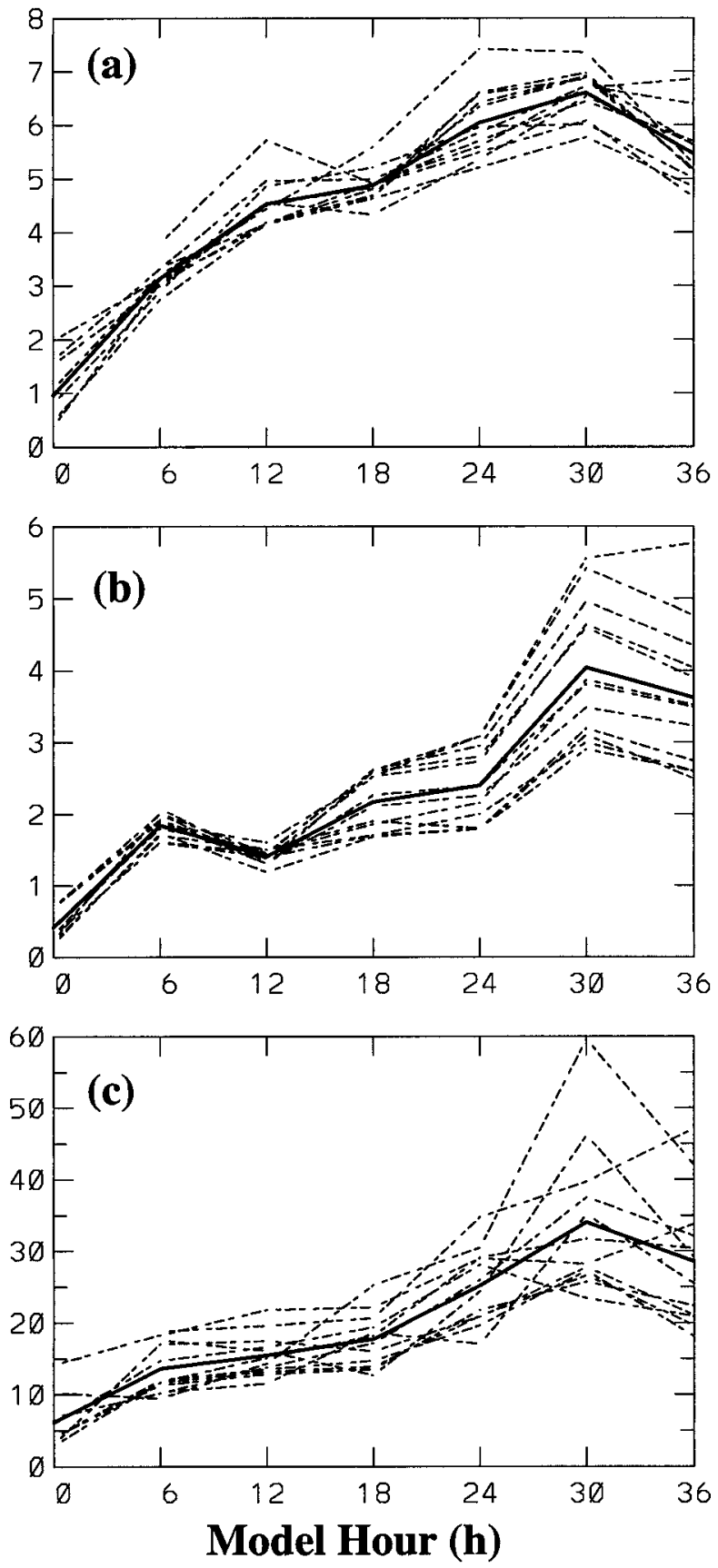

FIG. 3. Time series of rms errors (dashed), as calculated against the RPN-prepared analyses, for COMPARE models: (a) Wind speed $\left(\mathrm{m} \mathrm{s}^{-1}\right)$ at $300 \mathrm{hPa},(\mathrm{b})$ temperature $\left({ }^{\circ} \mathrm{C}\right)$ at $850 \mathrm{hPa}$, and (c) geopotential height $(\mathrm{m})$ at $300 \mathrm{hPa}$. Composite scores are given in thick solid lines.

Figure 3 displays the time series of domain averaged root-mean-square (rms) errors, as calculated against the RPN-prepared analyses, over the verification domain given in Fig. 4, for wind speed, temperature, and geopotential height for each of the participants in COMPARE. Specific features of concern are the increasing magnitude and range of rms errors with time. The results from Figs. 1 and 3 point to significant variability in the performance among individual models in simulating a case of explosive oceanic secondary cyclogenesis.

The objective of this paper is to perform a series of sensitivity tests, using one of the COMPARE models, in an effort to understand better the crucial physical processes associated with the predictability of the secondary cyclogenesis. This understanding may provide insight into why the simulations from COMPARE are so variable. It should be mentioned that this storm has been simulated by Mailhot and Chouinard (1989) using the Canadian regional finite-element (RFE) model with a grid size of $100 \mathrm{~km}$, verifying against a coarse (300 $\mathrm{km}$ ) horizontal resolution objective analysis. Their study focuses, in part, on the role of the low-level jet and its coupling with the moisture field during the rapid deepening phase of the IOP-14 storm. Here we use higherresolution analyses and model simulations to aid in the identification of important mesoscale structures (in the sea level pressure and surface latent heat flux fields), which are important to the predictability of the IOP-14 storm. In addition, we examine the hypothesis of Kuo et al. (1991) that surface energy fluxes during the preconditioning period are important by means of a quantitative quasi-Lagrangian moisture budget. The next section describes the mesoscale model used for this study. Section 3 provides a brief synoptic overview of the storm and outlines the experiment design. Section 4 discusses the results of the sensitivity tests. A summary and conclusions are given in the final section.

\section{Model description and initialization}

\section{a. MC2 model}

The model used for this study is the Mesoscale Compressible Community Model (MC2). The original version of the MC2 model has its roots in the semi-Lagrangian, semi-implicit, hydrostatic, primitive equation forecast model developed by Robert et al. (1985). Tanguay et al. (1990) relaxed the incompressibility assumption inherent in the primitive equations, generalizing the semi-implicit algorithm to integrate the fully compressible, nonhydrostatic Euler equations. A summary of the MC2 modeling system is provided in appendix A.

Three different resolvable-scale precipitation parameterizations to account for condensation under convectively stable conditions are used in the sensitivity experiments. The first one is a simple large-scale condensation scheme that removes moisture when the relative humidity in a layer exceeds a specified value. A majority of the COMPARE models utilized such a scheme. The second one is a predictive cloud-water scheme (Sundqvist et al. 1989) permitting a more advanced treatment of the mesoscale nature of clouds and precipitation systems. A fractional cloud cover within the model grid is 


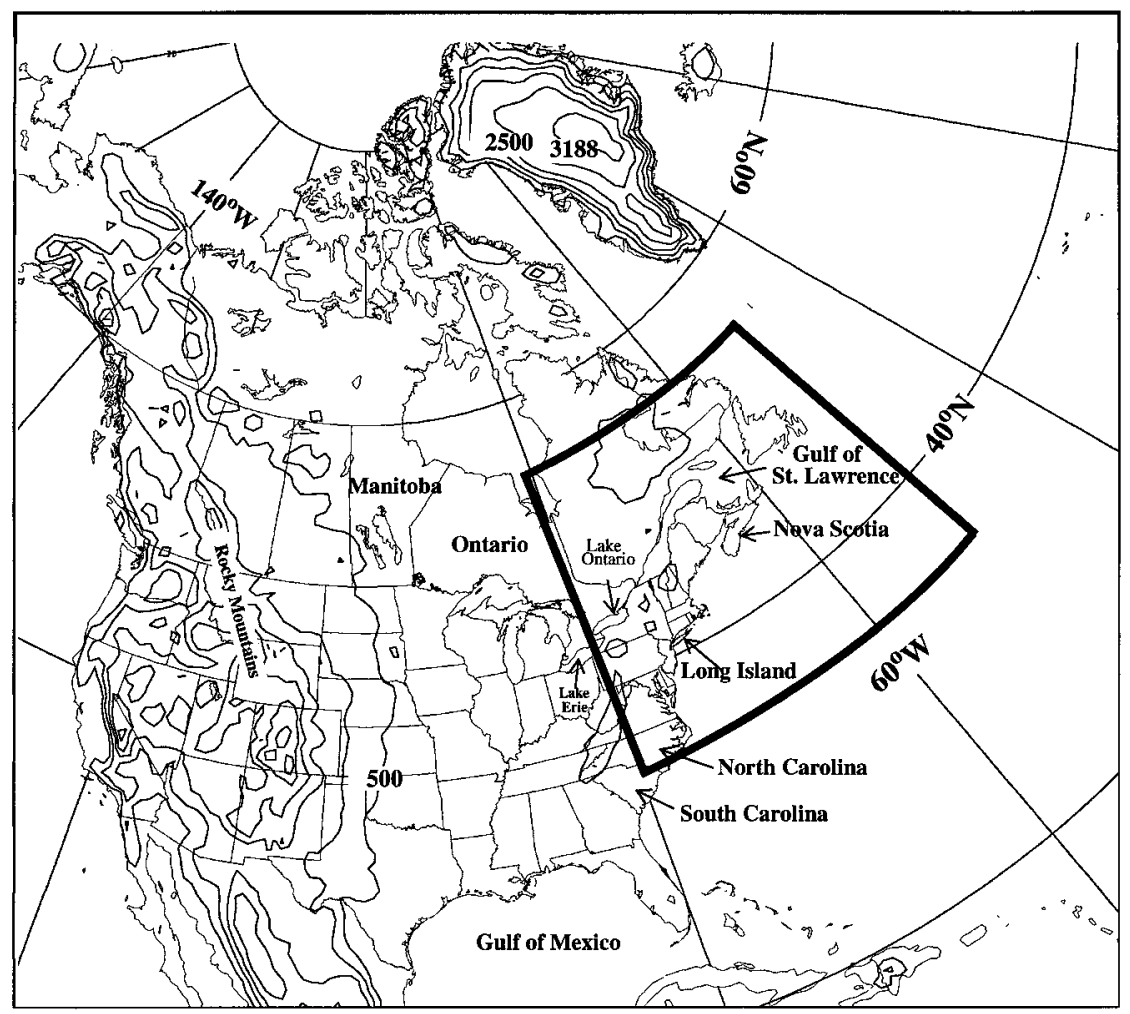

FIG. 4. MC2 model integration domain with topography. Orography shown at contours of 500 $\mathrm{m}$. The verification domain is shown in thick solid lines.

defined, allowing for the partitioning between precipitating water and cloud water. The third scheme follows Manabe et al. (1965), removing excessive moisture above a given relative humidity threshold. Unlike the first scheme, the effects of evaporation and freezing/ melting of precipitation are not included; the atmosphere is assumed to have zero carrying capacity and hence the excess moisture immediately condenses and precipitates. In each of the above schemes, the latent heat released is incorporated into the thermodynamic energy equation.

The impact of three convective parameterizations (Kuo, Manabe, and Fritsch-Chappell) is examined. These schemes were chosen based on their use among a wide spectrum of model performance in COMPARE. The Kuo scheme (Kuo 1974; Anthes 1977) defines a convectively active layer as being a conditionally unstable layer with a net positive moisture convergence (due to large-scale moisture convergence and surface evaporation). A fraction of this moisture is used to humidify the layer, while the remaining moisture condenses and precipitates, heating the atmosphere in the process.

In the version of the moist convective adjustment scheme (Manabe et al. 1965), conditional instability is removed by mixing adjacent levels (cooling below, heating above) to produce a lapse rate less than the dry adiabatic, the moist adiabatic, or a transitional combi- nation thereof. The scheme is triggered when conditional instability occurs with relative humidity in a given layer exceeding a critical value in the presence of upward motion. The relative humidity in the layer is constrained, after convective adjustment, to equal the value at the bottom, and hence an upward transfer of moisture is required. Any excessive moisture condenses and precipitates.

The Fritsch-Chappell (1980) scheme assumes that available buoyant energy, vertical wind shear, and vertical motion govern the evolution of deep convection. This scheme is well suited for grid sizes near $20 \mathrm{~km}$, because the scheme assumes that only one type of convective cloud controls the vertical fluxes of heat and moisture.

\section{b. Initialization}

All integrations are initialized at 1200 UTC 6 March 1986 and integrated for $36 \mathrm{~h}$. The initial conditions and subsequent 6-hourly analyses were generated by the regional data assimilation system at the Canadian Meteorological Centre (Chouinard et al. 1994). Additional data sources, including special buoy, ship, radiosonde, and aircraft dropsonde reports were obtained from the CASP and GALE observing networks and incorporated into the assimilation system.

The assimilation cycle produced 6-hourly analyses on 
a polar stereographic projection (true at $60^{\circ} \mathrm{N}$ ) with a $50-\mathrm{km}$ resolution in the horizontal shown in Fig. 4. This grid comprises the model integration domain. The meteorological fields of temperature, specific humidity, winds, and geopotential heights (hydrostatically balanced) are available on 44 isobaric levels, ranging from 1050 to $100 \mathrm{hPa}$ with a $25-\mathrm{hPa}$ resolution, and including the 70-, 50-, 30-, and 20-, and 10-hPa levels. To avoid problems associated with the lateral boundary conditions, a smaller domain (Fig. 4) over the CASP-GALE network is used for model verification (Chouinard et al. 1994).

\section{Case description and experimental design \\ a. Synoptic overview}

Figure 5 shows the RPN-prepared SLP analysis field at 12-h intervals for the period from 1200 UTC 6 March to 1200 UTC 7 March. At 1200 UTC 6 March, that is, the model initial time, a low pressure center $(999 \mathrm{hPa}$, denoted by L1) was situated over southwestern Lake Erie (Fig. 5a), having traveled eastward from the Canadian Rockies in the previous two days. A large-scale trough extended southward from the low center into the Gulf of Mexico. At $500 \mathrm{hPa}$, the flow was characterized by the presence of two troughs, one situated along the Manitoba-Ontario border, the other centered in the Ohio Valley (Fig. 6a).

By 0000 UTC 7 March, the low center had intensified and propagated eastward to a position over eastern Lake Ontario (Fig. 5b). The IOP-14 storm formed in an area south of Long Island within the preexisting cyclonic circulation associated with the surface trough extending southeast from the low center, as denoted by L2. For this reason, we consider this event as a case of secondary cyclogenesis. At this same time, at $500 \mathrm{hPa}$, the northernmost trough propagated eastward at a greater rate and the two short waves began to interact (Fig. 6b). A narrow zone of high potential vorticity (PV) (Hoskins et al. 1985) values extended southeastward between the two troughs.

Three circulation centers were present at 0600 UTC 7 March (Fig. 2), with the southeastern center representing the IOP-14 storm. The cyclone underwent its maximum deepening of $19 \mathrm{hPa} / 12 \mathrm{~h}$ to a position on the southwestern tip of Nova Scotia at 1200 UTC 7 March (Fig. 5c). Only a large-scale trough remained in the position of the former continental system. Numerous observing stations along the east coast of Canada and the United States reported significant amounts of precipitation. Also a secondary maximum in precipitation near Cape Cod was associated with the coastal circulation center shown in Fig. 2. Reports of thunder and lightning from some maritime stations indicated convective activity (Mailhot and Chouinard 1989). The two separate troughs at $500 \mathrm{hPa}$ had merged (Fig. 6c), and the IOP-14 storm was located beneath the right entrance
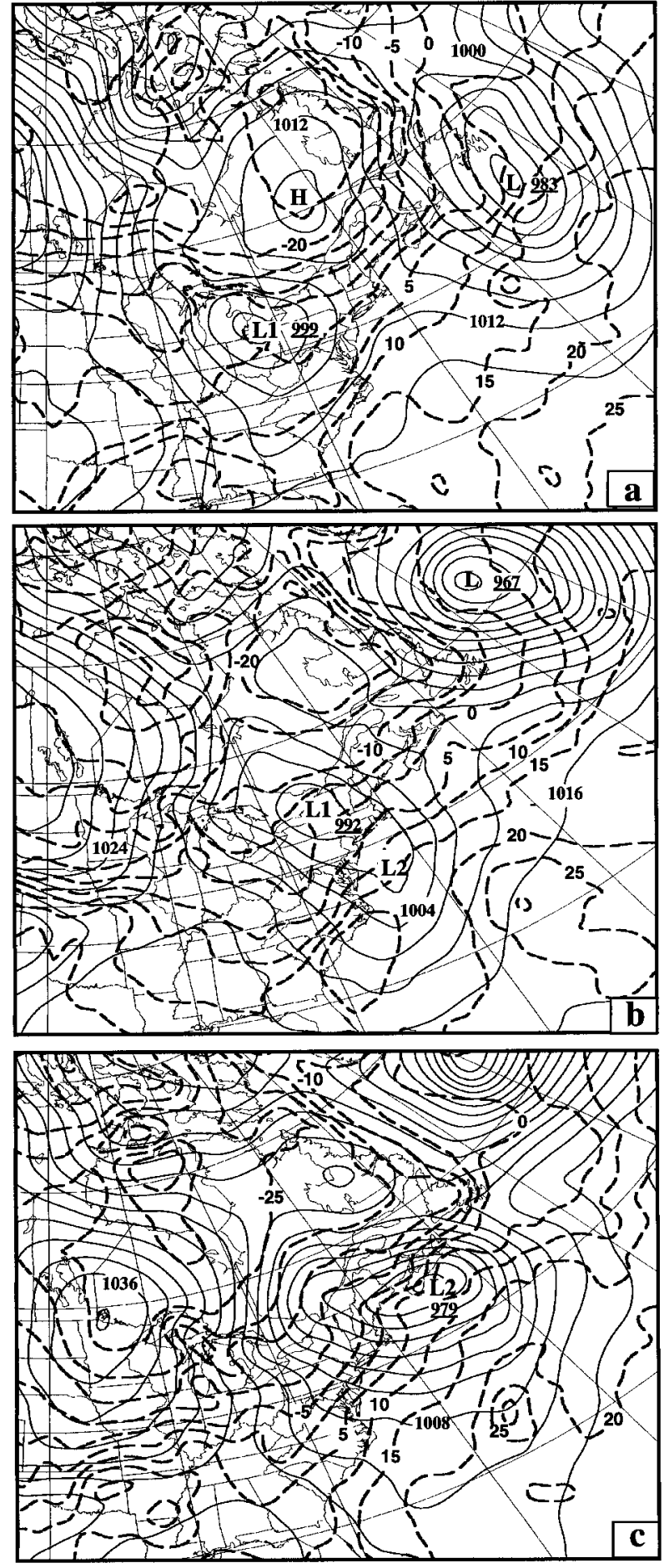

FIG. 5. RPN-prepared analyses SLP (solid) at intervals of $4 \mathrm{hPa}$ and surface temperature (dashed) at intervals of $5^{\circ} \mathrm{C}$ for (a) 1200 UTC 6 Mar, (b) 0000 UTC 7 Mar, and (c) 1200 UTC 7 Mar 1986. Note L1 denotes the primary continental low center, and L2 denotes the IOP-14 storm. Latitude-longitude lines are shown each $10^{\circ}$. 

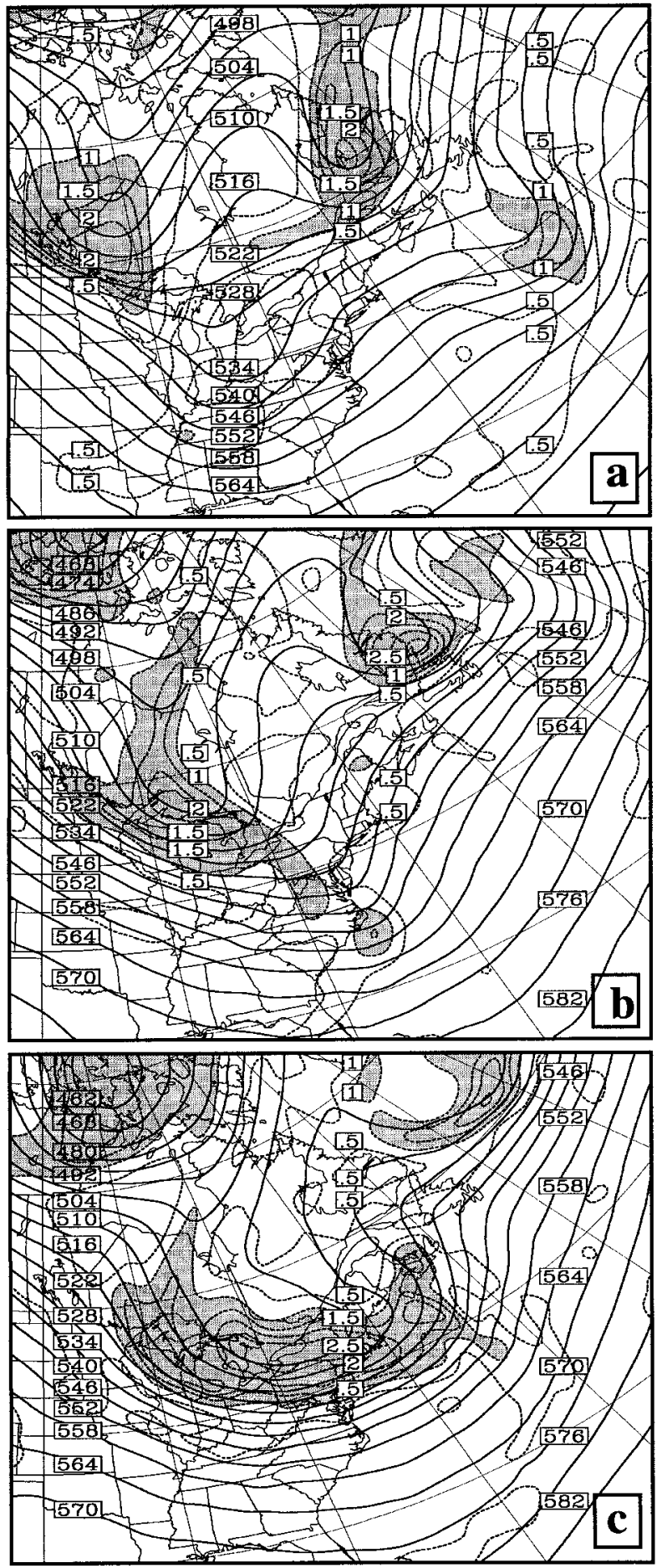

FIG. 6. RPN-prepared analyses 500-hPa height (solid) at intervals of 6 dam and PV (dashed) at intervals of 0.5 PVU for (a) 1200 UTC 6 Mar, (b) 0000 UTC 7 Mar, and (c) 1200 UTC 7 Mar 1986. Shaded regions denote PV values greater than 1.0 PVU. Latitude-longitude lines are shown each $10^{\circ}$. region of an upper-level jet streak associated with the diffluent trough, a favorable position for further deepening (Uccellini 1990).

The low continued to propagate to the north and east and resided in the Gulf of St. Lawrence with a central pressure of $973 \mathrm{hPa}$ at $0000 \mathrm{UTC} 8 \mathrm{March}$ (not shown).

\section{b. Experimental design}

Table 1 summarizes the sensitivity experiments. Nine 36-h simulations are conducted. Experiment CTL represents the full physics control simulation for the IOP14 storm. The model specifications used in the generation of the CTL run are listed in appendix A.

\section{1) Initial CONDITIONS}

Although an integration domain was suggested for COMPARE, each modeling institution was at liberty to devise its own integration grid, necessitating both horizontal and vertical interpolation of the original analyses. To examine the impact of small differences in the initial state introduced by interpolation on the 36-h integration, experiment PER is performed, in which the model initial conditions were perturbed by a combination of horizontal and vertical interpolation described in appendix B. The purpose of the above procedure is to start the MC2 model integration with vertical rms error profiles for wind speed, temperature, and geopotential height that were comparable to the largest rms errors seen among the COMPARE participants. In Fig. 7 , the range of rms errors as a function of pressure for COMPARE models at $0 \mathrm{~h}$ is plotted for (a) wind speed, (b) temperature, and (c) geopotential height, along with the rms errors generated by the interpolation procedure outlined in appendix B and the rms errors for CTL.

Our procedure reproduces well the large rms errors in wind speed (Fig. 7a) near 250 and $900 \mathrm{hPa}$. Similarly, the rms error maxima in temperature occur near the ground and at the tropopause level (Fig. 7b). Our perturbation in the geopotential height field (Fig. 7c) is biased toward lower rms error values below $400 \mathrm{hPa}$; however, we reproduce well the rapid increase above this level.

\section{2) Condensation schemes}

Daley (1981) argued that the presence of a moist convective adjustment scheme in numerical models may result in excessive predictability error growth rates. To examine the impact of latent heating on the secondary cyclogenesis and on the initial condition error growth, experiments CTLD and PERD are conducted, in which the convective parameterization scheme and latent heat feedback to the thermodynamic energy equation are removed from experiments CTL and PER, respectively.

The physics components of limited-area models include the treatment of phenomena occurring in the sur- 
TABLE 1. Summary of sensitivity experiments.

\begin{tabular}{|c|c|c|c|c|}
\hline Expt & Initial data & $\begin{array}{c}\text { Grid-scale } \\
\text { condensation }\end{array}$ & $\begin{array}{c}\text { Convective } \\
\text { parameterization }\end{array}$ & Remarks \\
\hline CTL (control) & RPN analysis & COND & KUO & \\
\hline PER (perturbed) & Perturbed RPN analysis & COND & KUO & \\
\hline CTLD (control dry) & RPN analysis & COND & None & $\begin{array}{l}\text { Thermodynamic feedback } \\
\text { of latent heat absent }\end{array}$ \\
\hline PERD (perturbed dry) & Perturbed RPN analysis & COND & None & $\begin{array}{c}\text { Thermodynamic feedback } \\
\text { of latent heat absent }\end{array}$ \\
\hline $\begin{array}{l}\text { SUND (predictive cloud-water } \\
\text { scheme) }\end{array}$ & RPN analysis & SUND & KUO & \\
\hline FC (Fritsch-Chappell) & RPN analysis & COND & $\mathrm{FC}$ & \\
\hline $\begin{array}{l}\text { MCA (moist convective adjust- } \\
\text { ment) }\end{array}$ & RPN analysis & SM & CA & \\
\hline SRS (simple radiation scheme) & RPN analysis & COND & KUO & $\begin{array}{l}\text { Solar radiation (Mailhot } \\
\text { 1994), infrared radiation } \\
\text { (Sasamori 1972) }\end{array}$ \\
\hline NR (no radiation) & RPN analysis & COND & KUO & No solar/infrared radiation \\
\hline
\end{tabular}

* RPN analysis corresponds to the RPN-prepared analyses. For grid-scale condensation schemes, COND refers to large-scale removal of supersaturation, while SUND denotes the predictive cloud-water scheme, and SM the stable Manabe scheme. For convective parameterizations, KUO refers to the Kuo scheme, FC the Fritsch-Chappell, and CA the Manabe convective adjustment.

face and planetary boundary layer, the generation of stable and convective precipitation, and short- and longwave radiative processes. The impact of various physical parameterizations on the forecast of explosive cyclogenesis demonstrates significant case-to-case variability (Mailhot and Chouinard 1989; Mullen and Baumhefner 1988). Two components related to model physics will be examined in the context of MC2 model sensitivity: 1) precipitation parameterizations, and 2) solar and infrared radiation schemes.

To determine the effect of different precipitation parameterizations on the IOP-14 storm, three sensitivity experiments are performed. In experiment SUND, the grid-scale condensation scheme is replaced by a predictive cloud-water scheme (Sundqvist et al. 1989), experiment FC employs the Fritsch-Chappell convective parameterization instead of the Kuo scheme, and in experiment MCA, condensation and convective processes follow Manabe et al. (1965).

\section{3) RADIATION SCHEMES}

Among the COMPARE participants, different infrared and solar radiation schemes were used, with some participants neglecting radiative processes completely. This motivates us to examine the impact of utilizing a different radiation scheme from that used in experiment CTL or of completely removing radiative processes. Radiative effects are examined with two experiments. In experiment SRS, the treatment of infrared radiation follows Sasamori (1972) where the interaction with clouds is neglected and only absorptivity by water vapor and carbon dioxide are considered. The solar flux and absorption are modified by zenith angle, water vapor, clouds, atmospheric dust, and stratospheric ozone. In experiment NR the effects of both solar and infrared radiation are neglected.

\section{Results \\ a. Control simulation}

Figure 8a shows the time series of central SLP for the IOP-14 storm at 6-h intervals in the CTL run. The model captures very well the rapid deepening phase, but continues to deepen the storm after $30 \mathrm{~h}$, while the storm was observed to fill after this time. Between 12 and 30 $\mathrm{h}$, the observed storm deepened $27 \mathrm{hPa}$ as compared to $26 \mathrm{hPa}$ for the simulated storm. As for other model runs in COMPARE, the control simulation fails to reproduce one of the three mesocyclones (i.e., the coastal center) at $18 \mathrm{~h}$ into the integration (cf. Figs. 2, 9b). Nevertheless, the general circulation structures agree quite well with those of the RPN-analyzed fields.

The model-simulated track, given in Fig. 8b, shows that $12 \mathrm{~h}$ into the simulation, at 0000 UTC 7 March, the model places the low center approximately $300 \mathrm{~km}$ too far to the northeast. Note that the position of the low center in the RPN-prepared analyses is based on a geostrophic vorticity maximum at $1000 \mathrm{hPa}$ in the trough (see Fig. 5b), because there was no closed low at $1-\mathrm{hPa}$ resolution. If this same criteria, based on the geostrophic vorticity maximum at $1000 \mathrm{hPa}$, were used for experiment CTL (see Fig. 9a), then the position error would be much reduced. Subsequently, the model recovers at $18 \mathrm{~h}$, only to demonstrate a westward bias at $24 \mathrm{~h}$. This westward bias in the track for the IOP-14 storm was found to be a systematic error among the COMPARE participants (see Fig. 3 of Gyakum et al. 1996).

As will be seen later, surface fluxes play an important role in the secondary cyclogenesis. Thus, Fig. 9 shows the evolution of SLP and surface latent heat flux from the CTL simulation. At 0000 UTC 7 March (Fig. 9a), two regions of maximum surface latent heat flux are seen in the southern portion of the domain, with the 

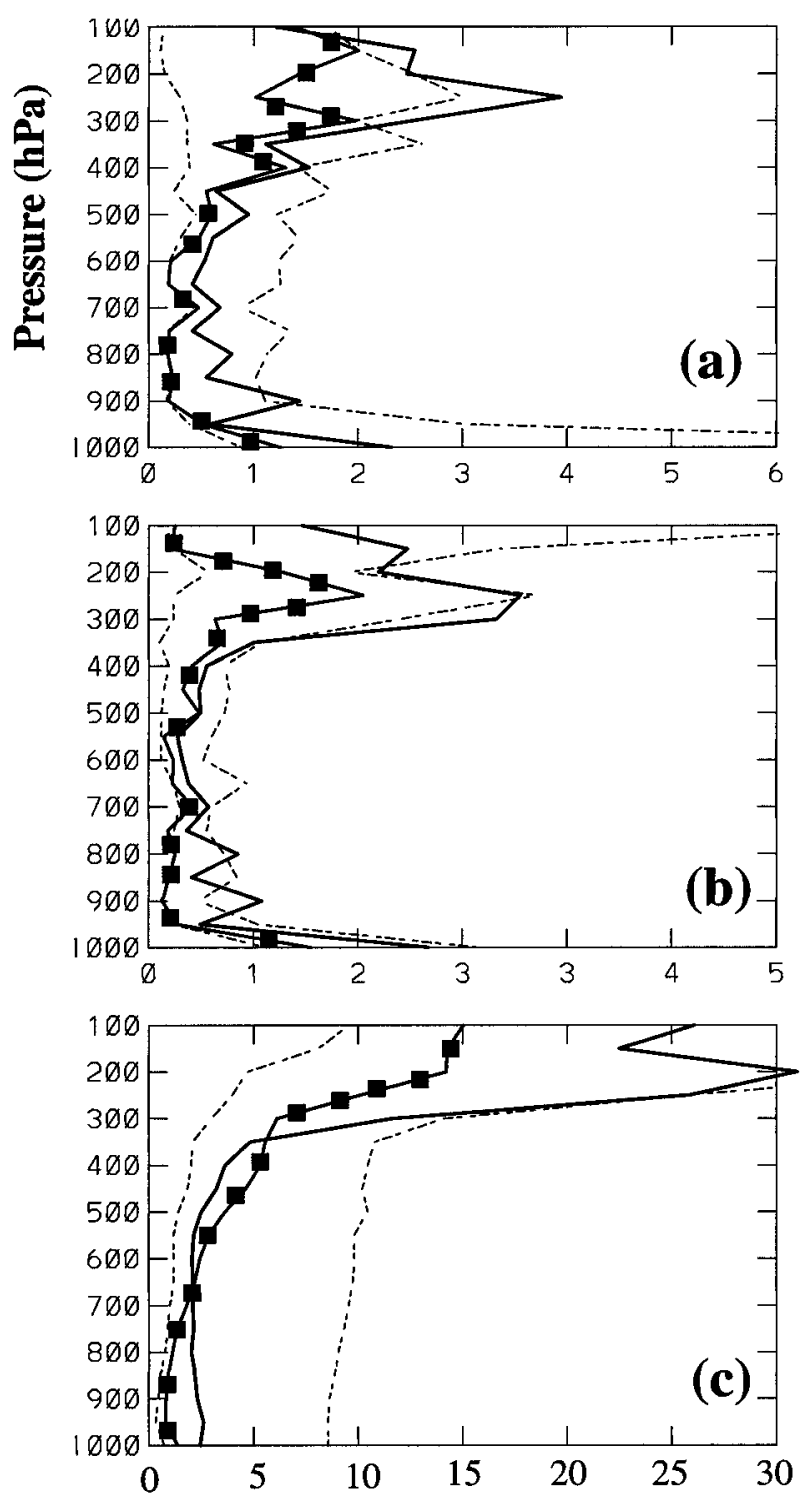

FIG. 7. Range of domain-averaged rms errors for COMPARE models (dashed) at 1200 UTC 6 Mar 1986 as a function of pressure for (a) wind speed $\left(\mathrm{m} \mathrm{s}^{-1}\right)$, (b) temperature $\left({ }^{\circ} \mathrm{C}\right)$, and (c) geopotential height $(\mathrm{m})$. Also plotted are the rms error vertical profiles for the described interpolation procedure (solid) and the CTL integration (squares).

easternmost extrema collocated with the genesis of the IOP-14 storm. Six hours later (Fig. 9b), the IOP-14 storm has propagated to the north and east in conjunction with the secondary maxima in latent heat flux. At this time, the area of maximum sensible heating (not shown) extends eastward from the Carolina coastline to a position south of the low center. The total surface heat fluxes are maximized $\left(>1000 \mathrm{~W} \mathrm{~m}^{-2}\right)$ in a narrow band near $38^{\circ} \mathrm{N}$ and $65^{\circ} \mathrm{W}$, south of the low center. This region corresponds to a southerly low-level jet zone (as shown by surface wind vectors), acting to amplify the upward sensible and latent heat fluxes as well as the moisture (a)

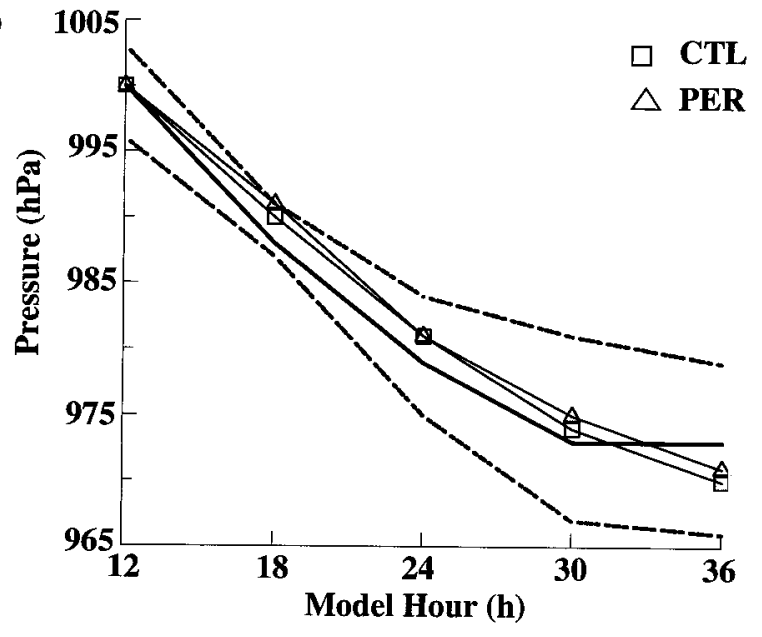

(b)

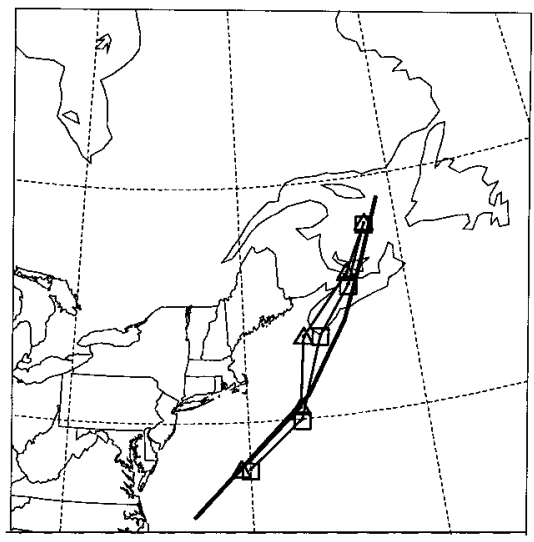

FIG. 8. (a) Traces of central SLP for the IOP-14 storm. The range of SLP values for COMPARE models is dashed. (b) Six-hourly cyclone positions starting from 0000 UTC 7 Mar 1986. In (a) and (b) the CTL experiment is given by open squares, the PER experiment by open triangles, and the RPN-prepared analyses is given in thick solid lines. Latitude-longitude lines in (b) are shown each $10^{\circ}$.

convergence (not shown) in the warm sector. The region of maximum total surface heat flux coincides with the region of maximum precipitation (see Fig. 10a). Bosart et al. (1995) found a similar magnitude of total surface flux $\left(>900 \mathrm{~W} \mathrm{~m}^{-2}\right.$; fluxes calculated from a standard bulk aerodynamic formula) for a case of east coastal cyclogenesis.

\section{b. Control dry simulation}

To see how latent heating affects the development of the IOP-14 storm, let us examine the "dry" simulation (CTLD). Of importance is that this simulation fails to develop a secondary cyclone offshore; instead, a surface pressure trough is present (not shown). The strong impact of latent heating on east coastal cyclogenesis was also noted by Lapenta and Seaman (1992), in which the removal of latent heating resulted in the absence of secondary cyclogenesis.

Further insight into the role of moist physics can be 


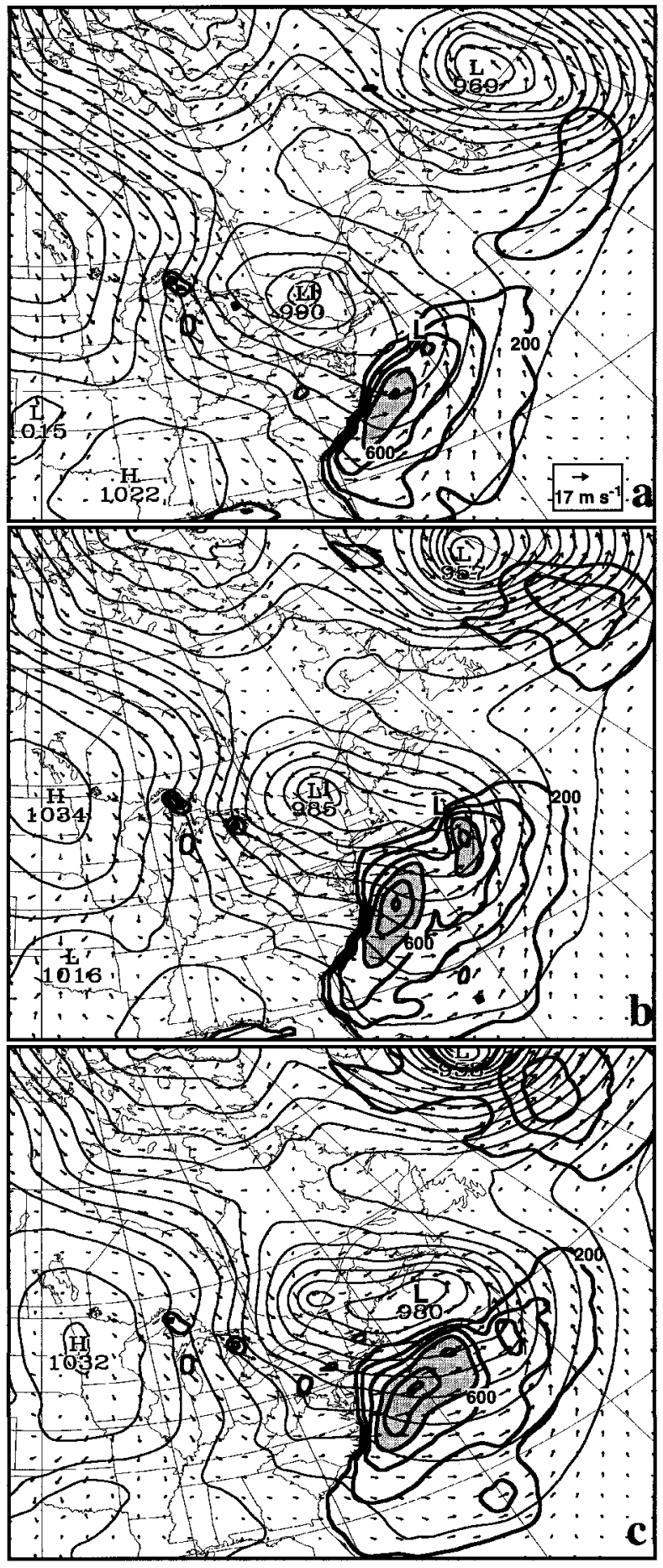

FIG. 9. SLP (thin solid) at intervals of $4 \mathrm{hPa}$, latent heat flux (thick solid) at intervals of $200 \mathrm{~W} \mathrm{~m}^{-2}$, and surface circulation vectors from CTL. Shaded regions denote latent heat flux values in excess of 800 W m²: (a) 0000 UTC 7 Mar, (b) 0600 UTC 7 Mar, and (c) 1200 UTC 7 Mar 1986. Note that L1 denotes the primary continental low center, and $\mathbf{L}$ denotes the IOP-14 storm. Latitude-longitude lines are shown each $10^{\circ}$ gained by examining the lower-tropospheric PV produced by latent heating (Reed et al. 1993; Davis and Emanuel 1991) from experiment CTL. We consider the PV field from 700 to $900 \mathrm{hPa}$ with 50-hPa vertical resolution. Figure 10a presents the layer-averaged (700$900 \mathrm{hPa}$ ) PV from the 18-h CTL simulation along with the 6-h total accumulated precipitation ending at the same time. A localized PV maximum is found in the vicinity of the low pressure center embedded within a large tongue of high PV. This area also coincides with a maximum in vertical motion at $700 \mathrm{hPa}$ (not shown). A zone of heavy precipitation $\left(>8.5 \mathrm{~mm} \mathrm{~h}^{-1}\right.$; instantaneous at $18 \mathrm{~h}$ ) extends to the southwest. Mailhot and Chouinard (1989) allude to the importance of condensation occurring near the low center, providing a means of destabilizing the lower troposphere when the heating maximum is occurring at lower levels. The area of maximum precipitation in experiment CTLD is less concentrated and nearly $10 \mathrm{~mm}$ (from 12 to $18 \mathrm{~h}$ ) less than in CTL (not shown), with weak vertical motion $(-3.80$ $\mathrm{Pa} \mathrm{s}^{-1}$ in CTL compared with $-0.76 \mathrm{~Pa} \mathrm{~s}^{-1}$ in CTLD; instantaneous at $18 \mathrm{~h}$ ) present near the position of the low center in CTL. The associated low-level PV maximum in CTLD is less than one-fourth the magnitude in CTL, further confirming the role of latent heating in producing this high $\mathrm{PV}$.

Figure 11 shows vertical profiles of the temperature and geopotential height differences between CTL and CTLD, averaged over an area $10^{\circ}$ latitude by $10^{\circ}$ longitude about the cyclone center in CTL at $18 \mathrm{~h}(0600$ UTC 7 March 1986). Throughout a deep layer in the troposphere (350-900 $\mathrm{hPa}$ ) temperatures are warmer in the presence of latent heating. The net warming is maximized at $600 \mathrm{hPa}$, which is close to $4^{\circ} \mathrm{C}$. Little heating occurs below $900 \mathrm{hPa}$. The deep layer net warming in the midtroposphere gives rise hydrostatically to lower heights below, being maximized near the surface, and higher heights aloft (i.e., a more pronounced downstream ridge) in experiment CTL. Clearly, latent heat release associated with both convective and grid-scale precipitation tends to warm the low-to midtroposphere, producing a significant low-level PV maximum acting to induce a robust cyclonic flow at the surface.

\section{c. Sensitivity to initial perturbations}

Figure 8a also depicts the central pressure trace for experiment PER. Small differences of 1-2 hPa are found between the PER and CTL simulations, with the PER cyclone slightly less intense. As in experiment CTL, the PER low also continues to deepen after $30 \mathrm{~h}$. The track for experiment PER shows a greater westward bias at $24 \mathrm{~h}$, but recovers to a similar position as CTL at $36 \mathrm{~h}$ (Fig. 8b). The bifurcation of the track solution seems to occur after $18 \mathrm{~h}$, a result also found in COMPARE (see Fig. 3 of Gyakum et al. 1996). Nonetheless, the PER run is able to reproduce the explosive deepening of the low and its northeast propagation, with only minor 

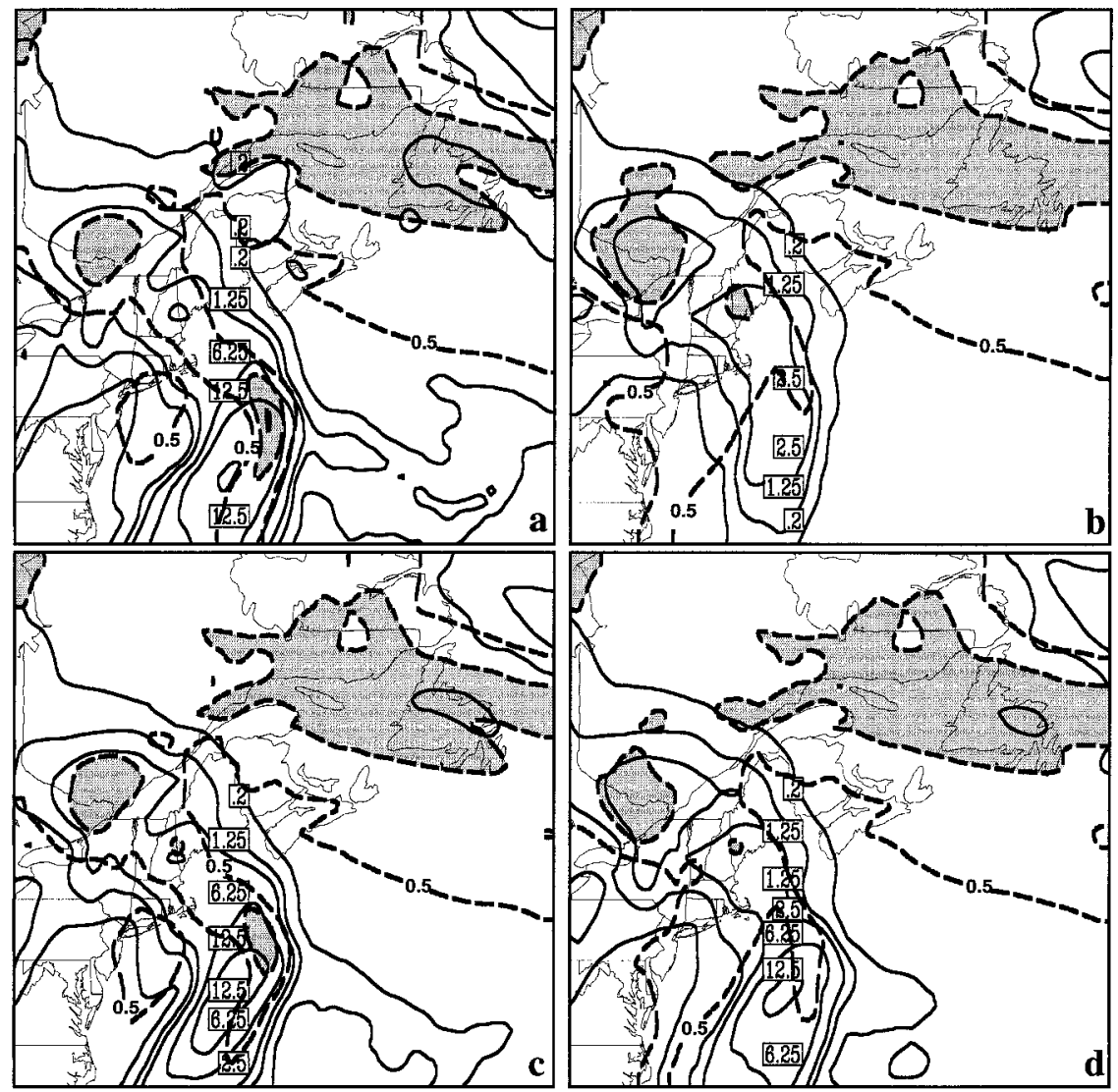

FIG. 10. Layer-averaged (700-900 hPa) PV (dashed) at intervals of $0.5 \mathrm{PVU}$ for $0600 \mathrm{UTC} 7$ Mar 1986, and 6-h total accumulated precipitation (solid) ending at 0600 UTC 7 Mar 1986. Contours for precipitation are for $0.2,1.25,2.5,6.25$, and 12.5 , and $25.0 \mathrm{~mm}$. Shaded regions denote PV values greater than 1.0 PVU: (a) CTL, (b) NEV, (c) 12EV, and (d) EV24.

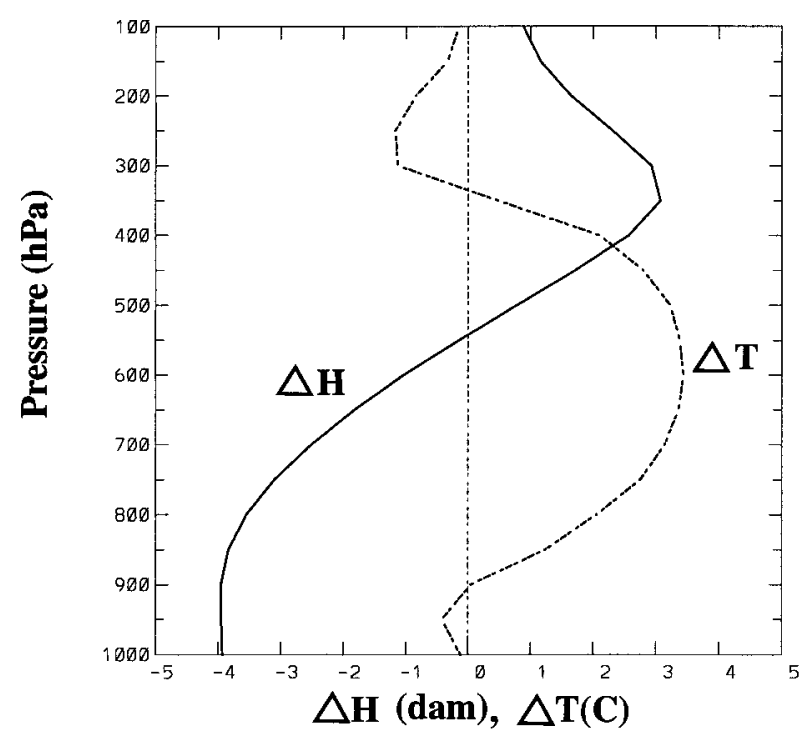

FIG. 11. Vertical profiles of areal averaged differences of geopotential height (solid) and temperature (dashed) between CTL and CTLD (CTL - CTLD). Average taken over an area $10^{\circ}$ latitude by $10^{\circ}$ longitude about the cyclone center in CTL at 0600 UTC 7 Mar 1986. differences from the CTL storm in terms of central SLP and 6-h positions.

To help understand the differences between experiments PER and CTL, Fig. 12 displays the time-pressure cross sections of the rms differences of wind speeds, temperature, and geopotential height between the two runs. Note that rms differences refer to differences between a sensitivity experiment and the CTL experiment, while rms errors are calculated between the given experiment and RPN-prepared analyses. At the initial time, all the three fields show the greatest rms differences above $300 \mathrm{hPa}$, owing to the large voids in the vertical structure above this level (see Table 3 ). The initial rms difference for wind speed (Fig. 12a) at 250 $\mathrm{hPa}$ is greater than $3.0 \mathrm{~m} \mathrm{~s}^{-1}$, by $18 \mathrm{~h}$ it decreases to less than $2.0 \mathrm{~m} \mathrm{~s}^{-1}$, and at $36 \mathrm{~h}$, it is less than $1.5 \mathrm{~m}$ $\mathrm{s}^{-1}$. A more gradual decay occurs below $500 \mathrm{hPa}$. The maximum rms difference at $300 \mathrm{hPa}$ (Fig. 12b) for temperature decreases from a value of greater than $2.5^{\circ} \mathrm{C}$ at $0 \mathrm{~h}$ to a value close to $0.5^{\circ} \mathrm{C}$ by $36 \mathrm{~h}$. However, between 100 and $200 \mathrm{hPa}$, the rms difference shows some limited growth between 0 and $12 \mathrm{~h}$, slowly decaying thereafter. The rms difference for geopotential 

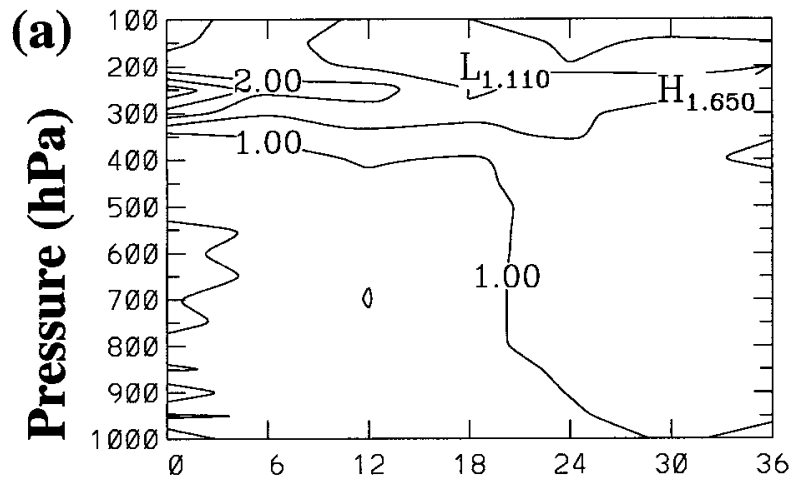

(b)

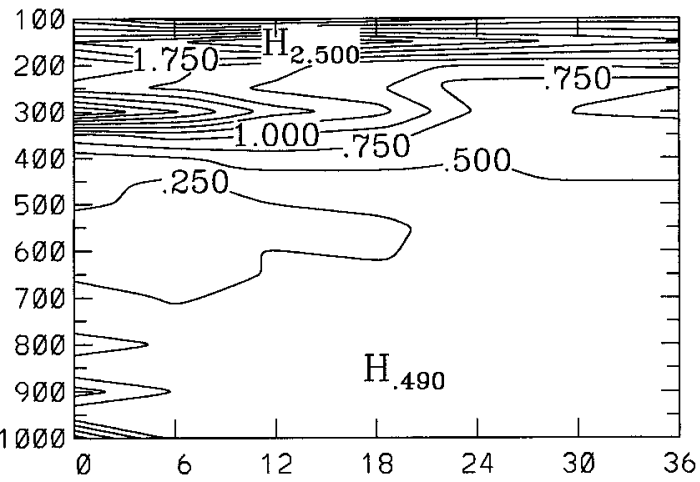

(c)

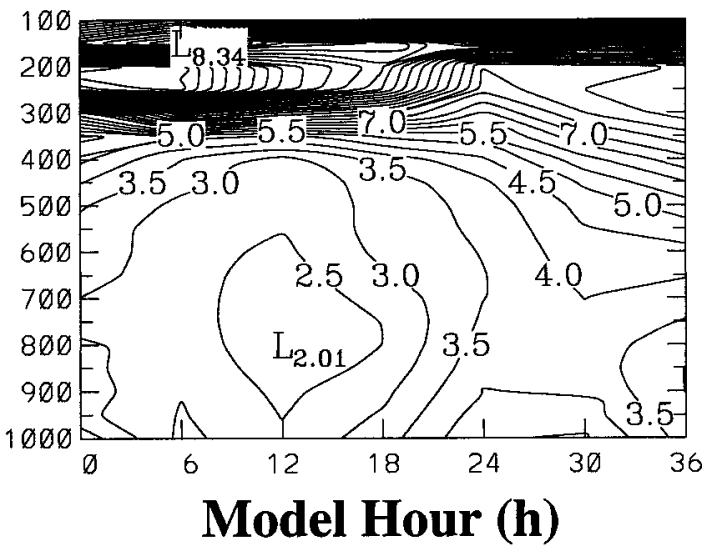

FIG. 12. Time series of rms differences for PER simulation, as calculated based on the CTL simulation for (a) wind speed at intervals of $0.5 \mathrm{~m} \mathrm{~s}^{-1}$, (b) temperature at intervals of $0.25^{\circ} \mathrm{C}$, and (c) geopotential height at intervals of $0.50 \mathrm{~m}$.

height (Fig. 12c) is sensitive to the perturbation procedure with values initially exceeding $18 \mathrm{~m}$ near 200 $\mathrm{hPa}$. These rms difference values decay quickly with time, reflected by the near-vertical inclination of the contours.

As in experiment CTLD, experiment PERD is unable to develop a secondary cyclone offshore. The time evolution of the rms differences for experiment PERD, as verified against experiment CTLD (not shown), demonstrates a structure similar to the full physics simulations, with smaller magnitudes for wind speed and geopotential height below $400 \mathrm{hPa}$.
The similarities between experiments CTL and PER in both the SLP trace and 6-hourly positions (Fig. 8), combined with the decay in the domain-averaged rms differences (Fig. 12), suggest that the IOP-14 storm is relatively insensitive to this type of initial condition perturbation. This result is consistent with previous studies (e.g., Anthes et al. 1985; Anthes et al. 1989; Errico and Baumhefner 1987), which show the minor impact of small variations in the initial conditions on limited-area model simulations when the observed lateral boundary conditions are used. Vukicevic and Errico (1990) argue that the use of observed lateral boundary conditions artificially increases predictability by (i) placing an upper wavelength limit on the horizontal scales that are free to evolve according to the model dynamics, and (ii) advecting error-free large-scale forcing into the limited regional domain.

For the present case, Yau and Jean (1989) conclude that the rapid deepening was initiated with the merger of two upper-level shortwave troughs, providing significant cyclonic vorticity advection over a preexisting low-level baroclinic zone in the New England states. Mailhot and Chouinard (1989) note that during rapid deepening the IOP-14 storm was located in the right entrance region of an upper-level jet, a favorable position for subsequent intensification. We believe that both the upper-level baroclinic wave and low-level stationary forcing over the Gulf Stream determined the development of the storm such that small-magnitude rms errors could not amplify. The use of the analyzed fields at lateral boundaries may also limit the growth of the rms errors.

Within the context of the COMPARE experiment, the MC2 model may have benefited more than other models from the use of the RPN-prepared initial and boundary conditions provided by the similar RFE model. It is possible that an initial perturbation similar to that introduced into experiment PER could result in much larger error growth and westward track bias, if introduced into a completely different model formulation.

\section{d. Sensitivity to precipitation parameterization}

Figure 13 compares the central SLP traces and 6-hourly positions from experiments SUND, FC, and MCA. All three simulations capture the rapid deepening phase of the IOP-14 storm, with experiment MCA closer to the observed SLP out to $30 \mathrm{~h}$. Experiments SUND and MCA continue to deepen the low after $30 \mathrm{~h}$, whereas the FC cyclone is consistently weaker, especially after $24 \mathrm{~h}$. Note that experiment FC produces an excessively weak system at $18 \mathrm{~h}$, lying outside the range of all COMPARE models. The positions of the storm vary between different simulations (Fig. 13b). The FC cyclone is closest to the observed at $12 \mathrm{~h}$, but diverges from the CTL track after $18 \mathrm{~h}$, with a westward position error of approximately $350 \mathrm{~km}$ at $24 \mathrm{~h}$. In contrast, the 
(a)

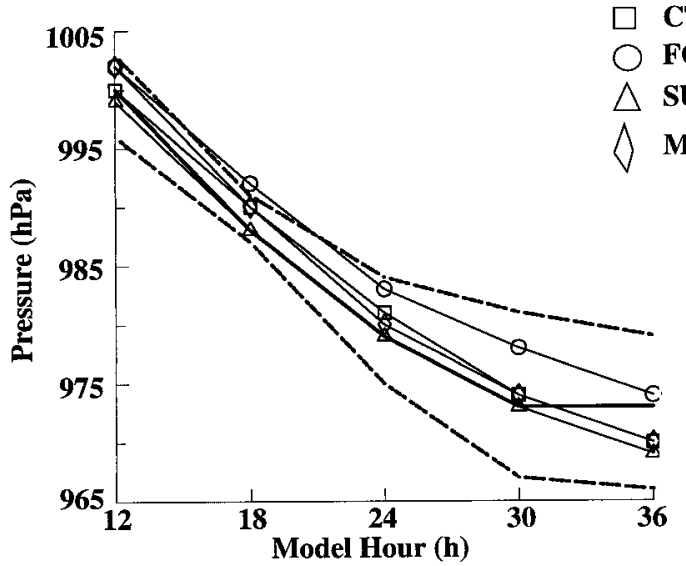

(b)

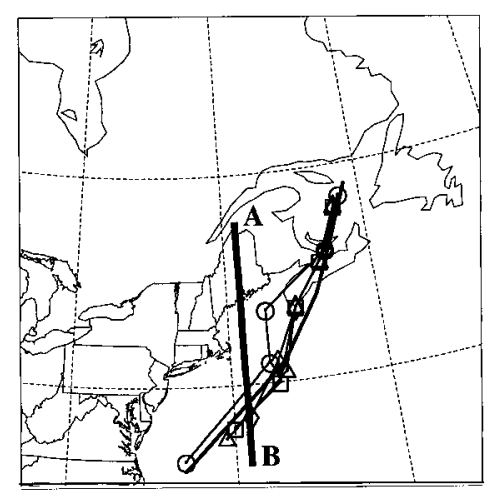

FIG. 13. As in Fig. 8 but experiment SUND is given by open triangles, FC by open circles, and MCA by open diamonds. Line A$\mathrm{B}$ in (b) indicates position of cross section in Fig. 15.

SUND and MCA cyclones maintain an eastward track throughout the $36-\mathrm{h}$ period.

To help understand the differences among the different sensitivity runs, Fig. 14a shows the time series of 6-h accumulated precipitation integrated over the verifying domain for experiments CTL, SUND, FC, and MCA. The 6-h accumulated precipitation increases from 12 to $30 \mathrm{~h}$ for each experiment. The largest differences are found at 6 and $36 \mathrm{~h}$ into the integration. Partitioning the 6-h accumulated precipitation into land and ocean portions indicates that larger variability occurs over the ocean (cf. Figs. 14b,c). Experiment FC generates the smallest precipitation accumulations between 12 and 24 $\mathrm{h}$, with the weakest layer-averaged PV center at $18 \mathrm{~h}$ offshore (not shown), consistent with the exceptionally weak system at $18 \mathrm{~h}$. Experiments SUND and CTL produce the greatest accumulations. The differences can be explained by the fact that the FC scheme tends to stabilize the atmospheric column and removes moisture more than other schemes. The presence of the scheme's moist downdrafts, which act to cool and dry the atmospheric column, may be important in enhancing the stability. A north-south cross section of the potential temperature difference between experiments FC and CTL in Fig. 15 shows that the marine environment south (a)

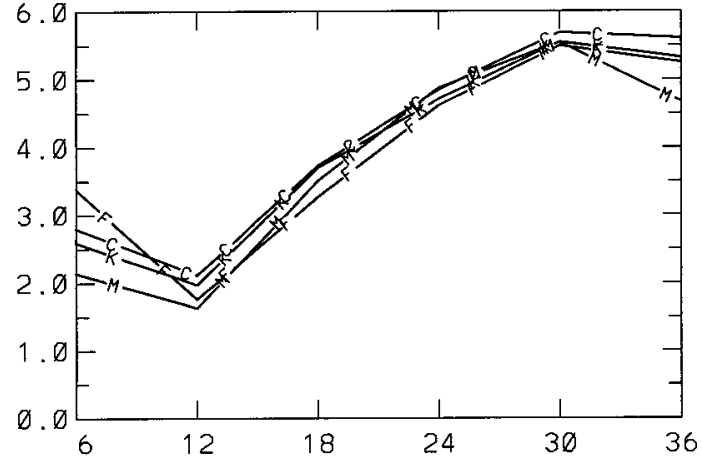

(b)

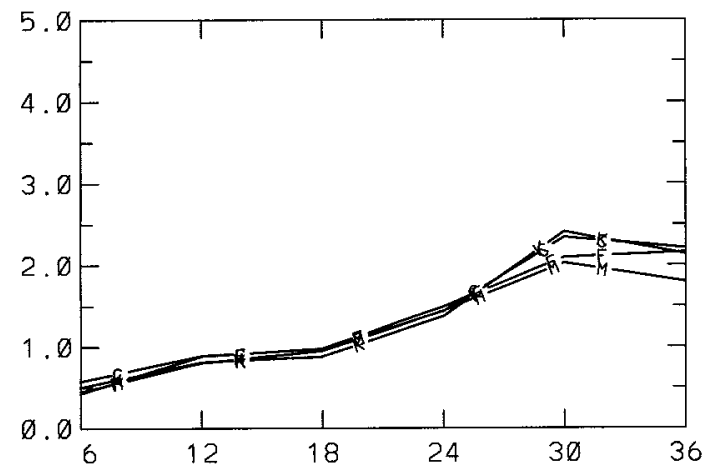

(c)

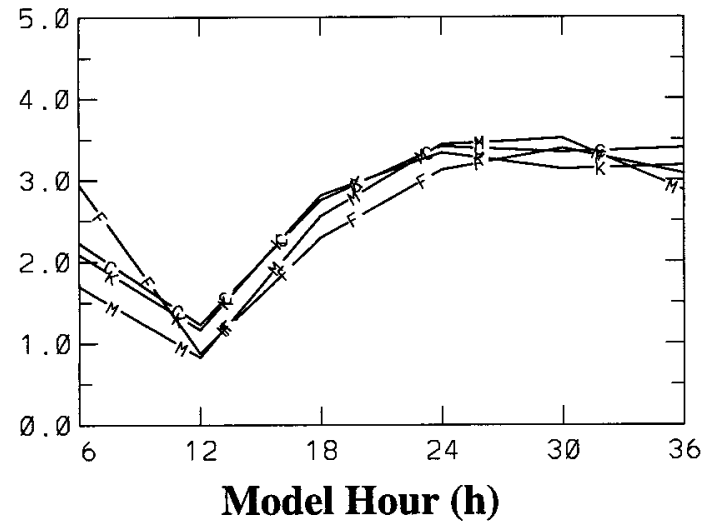

FIG. 14. Time series evolution of 6-h total precipitation accumulation ending at the given model hour for (a) verification domain, (b) land domain, and (c) ocean domain. Ordinate shows precipitation accumulations in $\mathrm{mm}$. The CTL simulation is denoted by " $\mathrm{C}$," SUND by "K," FC by "F," and MCA by "M."

of $40^{\circ} \mathrm{N}$ in experiment $\mathrm{FC}$ is colder and more statically stable in a deep layer $(1000-450 \mathrm{hPa})$. This also tends to produce weaker baroclinicity in the lower levels.

\section{e. Sensitivity to radiation parameterization}

The three radiation sensitivity experiments (e.g., experiments CTL, SRS, and NR) each exhibit similar skill in reproducing the explosive deepening phase of the IOP-14 storm. Experiments NR and CTL simulate the same SLP after $36 \mathrm{~h}$. A trace of 6-hourly positions (not shown) for the low center also demonstrates little sensitivity to the treatment (or the neglect of) radiation. 


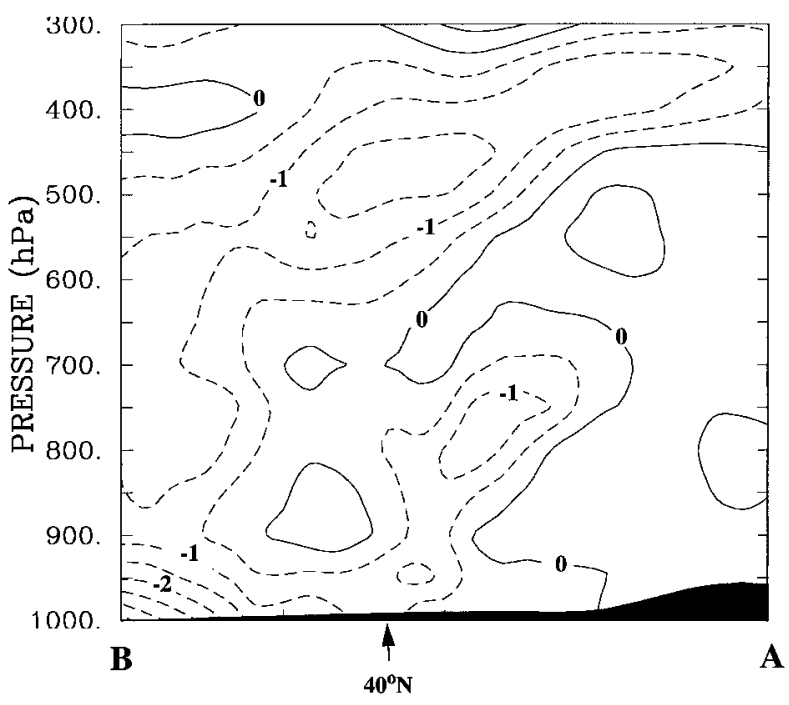

FIG. 15. Vertical cross section (shown in Fig. 13b) of potential temperature difference between FC and CTL (FC - CTL) at 0600 UTC 7 Mar 1986. Contour interval is $0.5 \mathrm{~K}$, with negative values dashed.

Larger variability in positions is noted at $18 \mathrm{~h}$; however, each of the simulated cyclones converges to the same location at $24 \mathrm{~h}$ and no bifurcation in the tracks is found as in the other sensitivity experiments.

When radiation processes are removed (i.e., experiment NR), the rms differences of temperature and geopotential height display a strong diurnal trend near the surface. Rapid growth in rms differences are found below $900 \mathrm{hPa}$ in the first $6 \mathrm{~h}$ because of the model initialization time in the early morning. The absence of radiation creates large temperature differences near the surface, values exceeding $4.0^{\circ} \mathrm{C}$ (four times greater than in any previous sensitivity experiment). Based on these results, we may state that the use of different radiative processes does not seem to contribute notably to the large variability in the deepening and 6-hourly positions of the cyclone. However, results from experiment NR indicate that when radiation processes are turned off, the variability in terms of rms differences at low levels is enhanced.

\section{f. Sensitivity to ocean surface evaporation}

Since the two dry runs (i.e., CTLD and PERD) were the only integrations that were unable to develop a sec- ondary cyclone offshore, the precipitation production and its feedback must have played an important role in producing the IOP-14 storm. Using an analytical baroclinic model (Sanders 1971), Yau and Jean (1989) attribute approximately half of the observed deepening of the IOP-14 storm to quasigeostrophic forcing and the rest to the influences of surface sensible and latent heat fluxes. Mailhot and Chouinard (1989) show that the RFE model with a grid size of $100 \mathrm{~km}$ fails to develop the secondary cyclone in the absence of surface evaporation. On the other hand, studies pertaining to the impacts of surface energy fluxes throughout the entire life cycle of cyclones show both positive (Mailhot and Chouinard 1989; Reed et al. 1993) and negligible effects (Kuo and Reed 1988; Reed and Simmons 1991). However, Kuo et al. (1991) show the importance of surface energy fluxes during the preconditioning period. This motivates us to examine the timing of the surface fluxes in producing the IOP-14 secondary cyclone.

To examine the impact of the air-sea interaction on the IOP-14 cyclogenesis, we perform three additional sensitivity experiments (see Table 2). In experiment $\mathrm{NEV}$, evaporation from the ocean surface is removed throughout the entire 36-h integration, as in Mailhot and Chouinard (1989), while keeping all the other parameters identical to the CTL run. Experiment $12 \mathrm{EV}$ is performed, in which evaporation from the ocean surface is allowed in the first $12 \mathrm{~h}$, but removed thereafter to test the hypothesis that the impact of surface fluxes is greater in the "preconditioning" period (Kuo et al. 1991). Experiment EV24 is conducted, in which evaporation is allowed only for the last $24-\mathrm{h}$ period of the simulation to assess the role of moisture flux during the rapid deepening phase.

Figure 16 compares the central SLP trace and 6-hourly positions from experiments CTL, 12EV, and EV24. In agreement with the results of Mailhot and Chouinard (1989), experiment NEV fails to develop an offshore circulation center. On the other hand, when evaporation from the ocean surface is permitted in the first $12 \mathrm{~h}$, the model is able to simulate the secondary cyclone offshore. From 12 to $24 \mathrm{~h}$, the central SLPs in CTL and $12 \mathrm{EV}$ agree to within $1 \mathrm{hPa}$; however, after $24 \mathrm{~h}$ experiment $12 \mathrm{EV}$ does not continue to deepen the low center as rapidly as that in CTL. The difference in central SLP between CTL and $12 \mathrm{EV}$ is $6 \mathrm{hPa}$ at the end

TABLE 2. Summary of surface moisture flux sensitivity experiments.

\begin{tabular}{lcc}
\hline \hline \multicolumn{1}{c|}{ Expt } & Surface fluxes & Remarks \\
\hline CTL (control) & $\begin{array}{c}\text { Both sensible and latent heat } \\
\text { fluxes } \\
\text { No ocean evaporation allowed }\end{array}$ & $\begin{array}{c}\text { Represents the control integration described in appendix A the impact of moisture fluxes from ocean sur- } \\
\text { face } \\
\text { Investigates the impact of moisture fluxes during early } \\
\text { stages of cyclogenesis } \\
\text { EV24 (evaporation last 24 h) }\end{array}$ \\
$\begin{array}{l}\text { Ocean evaporation turned on } \\
\text { for first } 12 \mathrm{~h} \\
\text { Ocean evaporation turned on } \\
\text { for last } 24 \mathrm{~h}\end{array}$ & $\begin{array}{c}\text { Investigates the role of moisture fluxes during the rapid } \\
\text { deepening stage }\end{array}$ \\
\hline
\end{tabular}




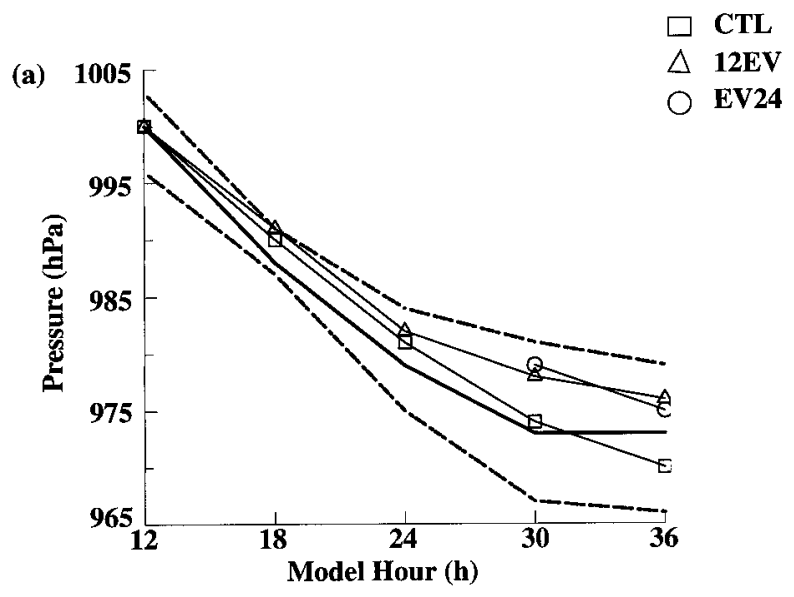

(b)

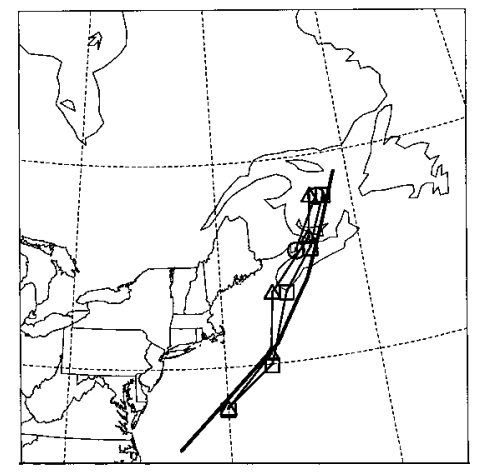

FIG. 16. As in Fig. 8 but expt $12 \mathrm{EV}$ is given by open triangles, and EV24 by open circles.

of the 36-h integration. When the surface evaporation is allowed only after $12 \mathrm{~h}$ into the integration, the model does not generate an offshore circulation center until 30 $\mathrm{h}$. This alludes to the importance of the moisture flux in the 12-h period preceding rapid cyclogenesis. Additional sensitivity experiments have been conducted, which involve a notable reduction in the initial water vapor content in a deep layer. These experiments show little impact on the evolution of the storm compared to that in experiment CTL, revealing again that the surface evaporation from the underlying warm ocean in the first $12 \mathrm{~h}$ plays an important role in the subsequent cyclogenesis.

A synoptic perspective of the differences between experiments CTL, NEV, $12 \mathrm{EV}$, and EV24 is provided in Fig. 17. The 850-hPa height and temperature fields are shown for all four experiments at 0600 UTC 7 March 1986 , along with the temperature differences at $850 \mathrm{hPa}$ between the given sensitivity experiment and the control run (experiment CTL). The large area of colder temperatures in experiment NEV (Fig. 17b), when compared to CTL, points to the importance of latent heating derived from surface evaporation acting to amplify the downstream ridge and increase the strength of the geostrophic warm advection (note the smaller area between the temperature and height contours in CTL as compared with NEV). A similar temperature difference is found in experiment EV24 (Fig. 17d), pointing to the importance of evaporation in the first $12 \mathrm{~h}$, which acts to precondition and warm the troposphere through latent heat release associated with precipitation. A similar pattern of geostrophic warm advection is seen when evaporation is allowed to precondition the environment in the early stages before cyclogenesis (experiment $12 \mathrm{EV}$; see Fig. 17c).

To gain further insight into the role of the surface moisture flux in the rapid deepening of the IOP-14 storm, let us compare the 700-900-hPa layer-averaged $\mathrm{PV}$ and the 6-h accumulated precipitation among experiments CTL, NEV, 12EV, and EV24. One can see little differences in structure and magnitude between CTL and 12EV (cf. Figs. 10a,c). In both runs, the area of maximum precipitation coincides with the region of maximum latent heat flux (cf. Figs. 9b and 10a,c), indicating the importance of the surface evaporation in providing additional moisture needed to bring the grid box to saturation. In experiments NEV (Fig. 10b) and EV24 (Fig. 10d), only a weak trough of higher PV is present offshore with a magnitude one-third that of CTL and $12 \mathrm{EV}$.

On the other hand, the absence of surface evaporation (experiment NEV) limits the moisture content in the lowest layers for the gridbox saturation and convective development, so the magnitude and area coverage of the low-level PV maximum are much smaller than those in CTL (cf. Figs. 10a,b). The 6-h accumulated precipitation is less than one-third of those in experiment CTL. In the case of experiment EV24 (Fig. 10d), the surface evaporation is turned on after $12 \mathrm{~h}$, but it does not match the baroclinic development because the model requires time to spin up and generate precipitation; hence total precipitation is halved from that of CTL. The effect of removing the surface evaporation after $12 \mathrm{~h}(12 \mathrm{EV})$ decreases the 6-h accumulated precipitation by about 5 $\mathrm{mm}$ (Fig. 10c).

An indirect effect of the precipitation and latent heat release is the amplification of the downstream ridge (Davis and Emanuel 1991). Potential temperature values calculated on the 2-PVU surface, termed the "dynamic tropopause," can neatly summarize the feedback of the lower level PV-induced circulation upon the upper-level temperature and height fields (Hakim et al. 1995). Thus, Fig. 18 compares the 18 -h simulated potential temperature structures on the dynamic tropopause among experiments CTL, CTLD, and NEV. Of interest is that experiment CTL shows a wavelike structure of the potential temperature (Fig. 18a), with a ridge axis situated to the west of Nova Scotia and a trough to the south of Long Island. Note that the ridging and troughing imply the lifting and depression of the tropopause, respectively, and the ridge corresponds to the area of intense precipitation (cf. Figs. 10a and 18a). However, this thermal wave is significantly weaker in both CTLD and $\mathrm{NEV}$, for example, with the potential temperature in the 

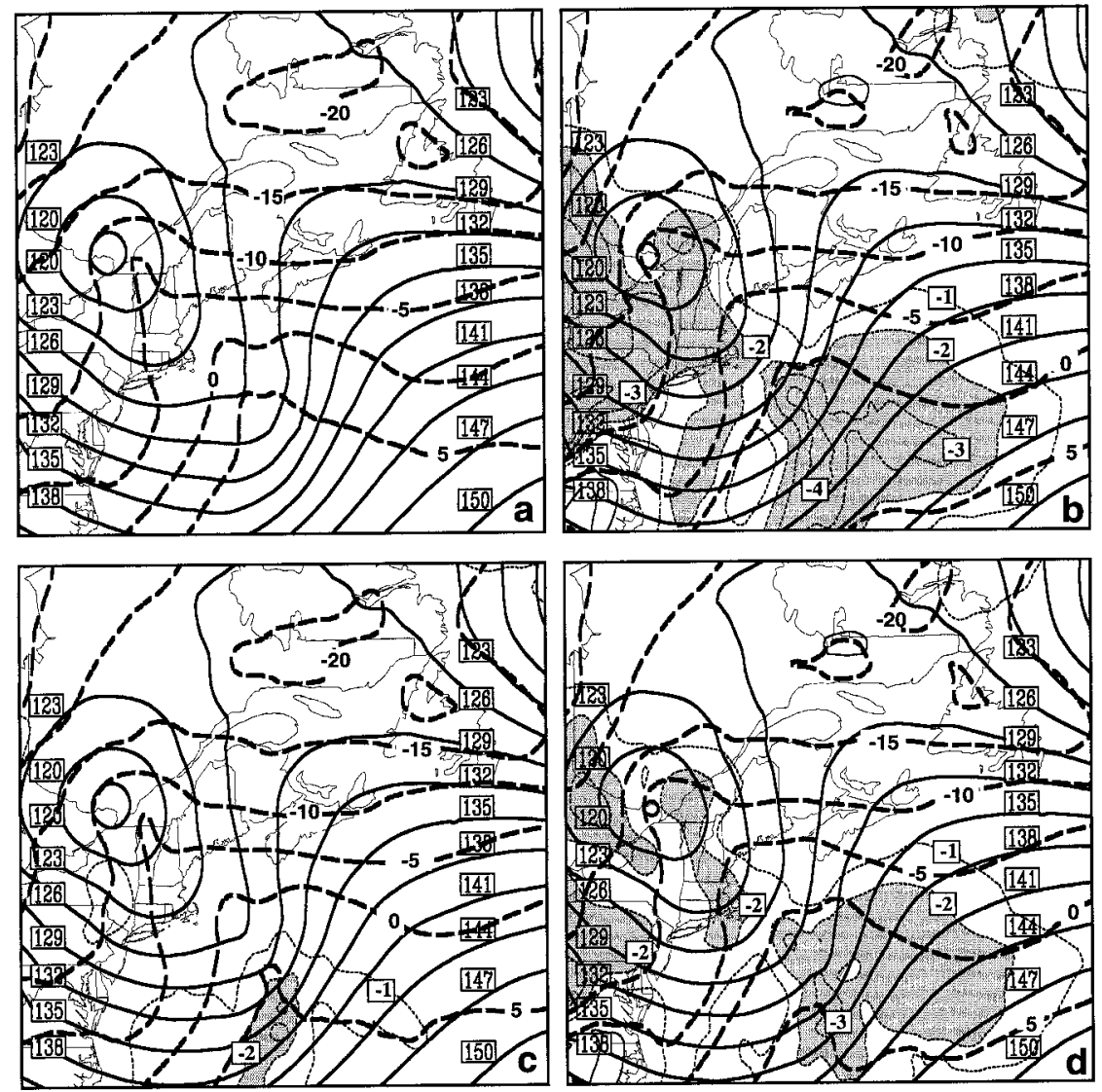

FIG. 17. Geopotential height (solid) at intervals of 3 dam and temperature (thick dashed) at intervals of $5^{\circ} \mathrm{C}$ at $850 \mathrm{hPa}$ for $0600 \mathrm{UTC} 7 \mathrm{Mar}$ 1986: (a) CTL, (b) NEV, (c) 12EV, and (d) EV24. In (b), (c), and (d) thin dashed lines show temperature difference at $850 \mathrm{hPa}$ between the given sensitivity experiment and experiment CTL (expt - CTL). Shaded region denotes a temperature difference of less than $-2^{\circ} \mathrm{C}$.

ridge $12 \mathrm{~K}$ cooler than that in CTL (cf. Figs. 18a-c). This difference is clearly a result of latent heat release that acts to locally warm the midtroposphere and lift the height of the tropopause. The similarity between Figs. $18 \mathrm{~b}$ and $18 \mathrm{c}$ suggests that the ocean surface evaporation is as important as latent heating in determining the present secondary cyclogenesis. This occurs because the preexisting low-level moisture is just close to saturation. Without the surface evaporation, the gridbox saturation could not be triggered at the right time and the right location.

When compared with large-scale extratropical cyclogenesis, where upper-level baroclinic forcings tend to dominate (Lackmann et al. 1996), this case of secondary cyclogenesis is different in that its occurrence is crucially dependent upon both latent heating and evaporation from the ocean surface. These results suggest that the variability in COMPARE (i.e., cyclone intensity and 6-hourly positions) may result from the precipitation generation processes in the models that are responsible for the creation of the low-level PV maximum.

\section{g. Water vapor budget}

To substantiate the important role of surface evaporation shown above, we perform a quasi-Lagrangian moisture budget (Kuo and Anthes 1984) for experiment CTL, using the equation (Trenberth and Guillemot 1995)

$$
P=-\boldsymbol{\nabla} \cdot \frac{1}{g} \int_{50 \mathrm{hPa}}^{p_{s}} q \mathbf{v}_{h} d p-\frac{\partial w}{\partial t}+E,
$$

where $w$ is the precipitable water defined by

$$
w=\frac{1}{g} \int_{50 \mathrm{hPa}}^{p_{s}} q d p,
$$

$q$ the specific humidity, $\mathbf{v}_{h}$ is the horizontal velocity, $p_{s}$ the surface pressure, $E$ the evaporation from the surface, and $P$ the precipitation. In (1) we introduce the total integrated moisture transport $\mathbf{Q}$, defined by

$$
\mathbf{Q}=\frac{1}{g} \int_{50 \mathrm{hPa}}^{P_{s}} q \mathbf{v}_{h} d p .
$$

In practice (1) is averaged over a horizontal area to 


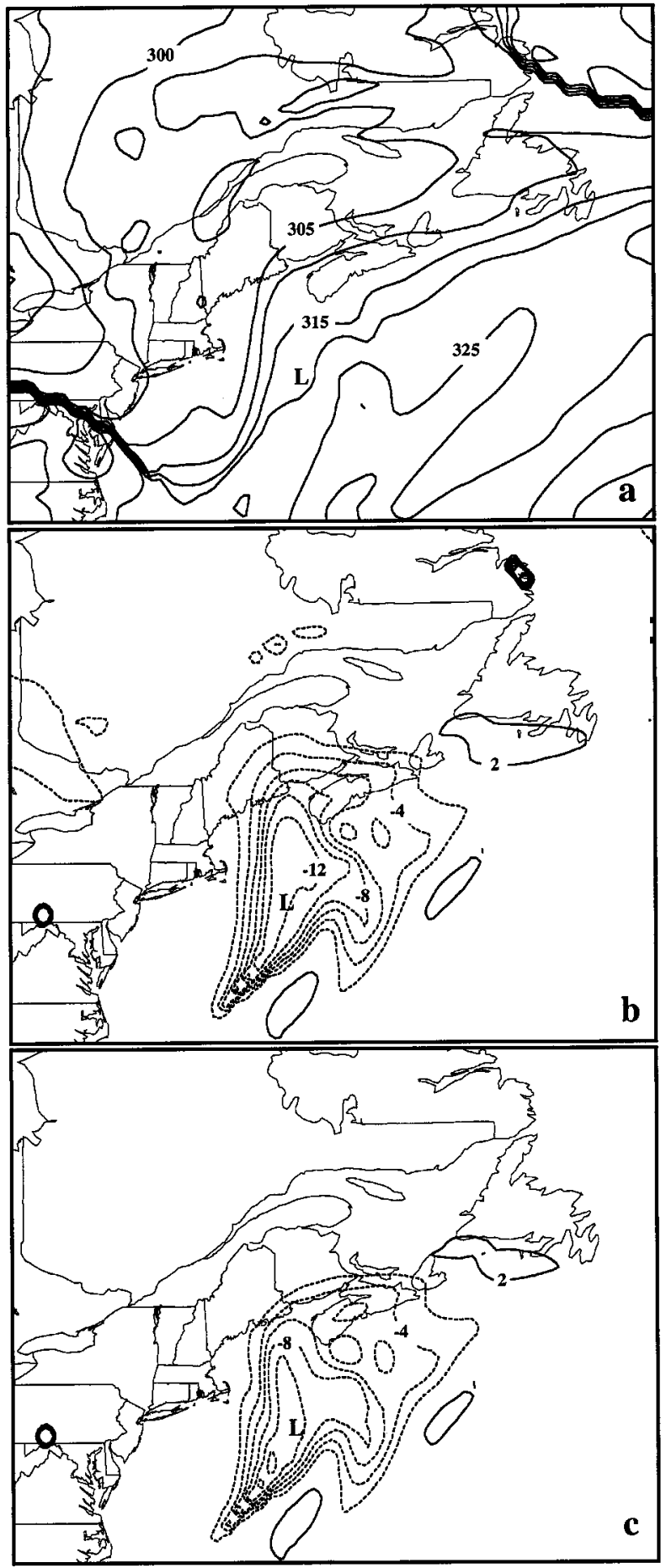

FIG. 18. Potential temperature on the dynamic tropopause (2-PVU surface) at 0600 UTC 7 Mar 1986: (a) CTL, (b) CTLD - CTL, and (c) NEV - CTL. Contour interval for (a) is $5 \mathrm{~K}$, while in (b) and (c) interval is $2 \mathrm{~K}$ with negative values dashed. Position of low center in CTL is given by $\mathbf{L}$. determine the various sources of water vapor contributing to precipitation. In this study we consider an area of size $850 \mathrm{~km} \times 1600 \mathrm{~km}$ coinciding with the region of maximum convective precipitation (see Fig. 19). Budget calculations were performed with a variety of box sizes, and the general findings were found to be robust.

The divergence of the time and area-averaged total integrated moisture transport $(-\boldsymbol{\nabla} \cdot \mathbf{Q})$ can be partitioned into contributions that include mass divergence in the presence of moisture $-q\left(\boldsymbol{\nabla} \cdot \mathbf{v}_{h}\right)$ and moisture advection $\left(-\mathbf{v}_{h} \cdot \boldsymbol{\nabla} q\right)$ (Bosart and Sanders 1981). Our computation of $(-\boldsymbol{\nabla} \cdot \mathbf{Q})$ will differ from the sum of $\left(-\mathbf{v}_{h} \cdot \nabla q\right)$ and $-q\left(\boldsymbol{\nabla} \cdot \mathbf{v}_{h}\right)$ due to the neglect of parameterized physics and the averaging techniques used. For each 6-h period, the time integration was performed by simply averaging the convergence and advection values at the beginning and end. The results are shown in columns 1, 2, and 3 of Table $3 \mathrm{a}$.

Convergence in the presence of water vapor is the dominant term contributing to the convergence of moisture transport for all four time periods. In fact, the vertically integrated moisture advection is dry, increasingly so with time. Between 6 and $12 \mathrm{~h}$ more water vapor is used for storage than falls as precipitation, but as the storm deepens, the storage (column 4) is depleted at the expense of precipitation (column 7). Throughout the entire period the contribution from evaporation is significant (column 5), exceeding that due to the local convergence in the presence of moisture from 6 to $12 \mathrm{~h}$. Columns 5-8 in Table 3 a compare the calculated values of evaporation and precipitation from the model simulation (experiment CTL) with those obtained as residuals in (1). The residual values for evaporation (precipitation) were calculated with the precipitation (evaporation) amounts derived from the model output. Although we neglected some parameterized processes and simply averaged all the terms at the beginning and end of each 6-h period, the differences are small.

In Table 3b, we scale the values in Table $3 a$ to obtain the relative contributions of the processes providing moisture to the budget area and those processes that act as sinks in the budget area. Note for evaporation and precipitation the model calculated values (Calc.) from CTL are used. Evaporation is the largest contributor of moisture (54\%) to the local storage over the budget area from 6 to $12 \mathrm{~h}$, with convergence in the presence of water vapor providing much of the remainder. The importance of evaporation as a moisture source diminishes somewhat as the integration evolves, but nonetheless its contribution is not insignificant, providing roughly $50 \%$ out to $30 \mathrm{~h}$. Precipitation amounts increase with time, depleting the storage.

\section{Summary and conclusions}

In this study, a series of sensitivity experiments have been performed using the Canadian MC2 model with a 

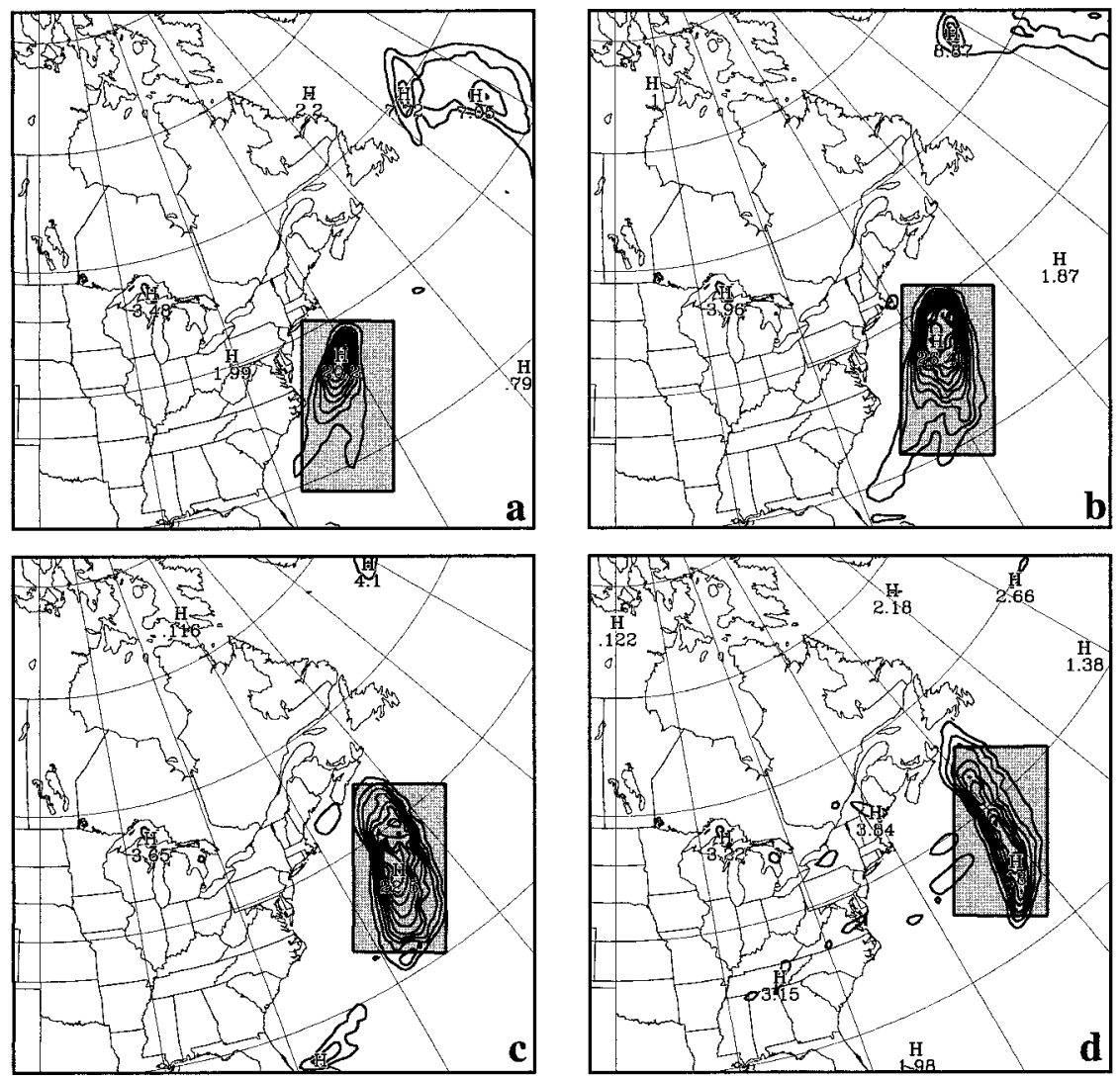

FIG. 19. Boxes used in calculating area-averaged water vapor budget. Size is $850 \mathrm{~km} \times 1600$ $\mathrm{km}$ for (a) 6-12, (b) 12-18, (c) 18-24, and (d) 24-30 h. Six-hour convective precipitation accumulation from CTL is contoured every $2 \mathrm{~mm}$.

grid size of $50 \mathrm{~km}$, in order to gain insight into the relative importance of various physical processes and initial-condition errors in simulating a case of explosive secondary marine cyclogenesis (IOP-14 storm) that occurred during the concurrent field programs of CASP and GALE in March 1986. Another objective is to provide a better understanding of the large variability in the simulation of the IOP-14 storm by the COMPARE models.

It is found that secondary cyclogenesis is most sen-

TABLE 3. Water vapor budget results from expt CTL (in mm, accumulated during the given 6-h period). Columns 1 and 2 of (a) are pressure integrals divided by g, Calc. refers to output from the model, while Res. refers to residual calculations based upon (1).

\begin{tabular}{|c|c|c|c|c|c|c|c|c|}
\hline \multicolumn{9}{|l|}{ (a) } \\
\hline $\begin{array}{l}\text { Time } \\
\text { period } \\
\text { (h) }\end{array}$ & $\stackrel{1}{1}-\mathbf{v}_{h} \cdot \nabla q$ & $\begin{array}{c}2 \\
-q\left(\boldsymbol{\nabla} \cdot \mathbf{v}_{h}\right)\end{array}$ & $\stackrel{3}{-\nabla} \cdot Q$ & $\begin{array}{c}4 \\
-\partial w / \partial \mathrm{t}\end{array}$ & $\begin{array}{c}5 \\
\text { E Calc. }\end{array}$ & $\begin{array}{c}6 \\
\text { E Res. }\end{array}$ & $\begin{array}{c}7 \\
\text { P Calc. }\end{array}$ & $\begin{array}{c}8 \\
\text { P Res. }\end{array}$ \\
\hline $6-12$ & -0.14 & 3.52 & 3.52 & -4.83 & 4.01 & 4.19 & 2.88 & 2.70 \\
\hline $12-18$ & -1.19 & 5.62 & 4.71 & -2.78 & 4.20 & 5.51 & 7.44 & 6.13 \\
\hline $18-24$ & -1.38 & 5.64 & 4.65 & -0.70 & 3.88 & 3.77 & 7.72 & 7.83 \\
\hline $24-30$ & -1.41 & 3.90 & 2.82 & 0.53 & 2.69 & 1.61 & 4.96 & 6.04 \\
\hline \multicolumn{9}{|l|}{ (b) } \\
\hline & \multicolumn{5}{|c|}{ Moisture available to budget area } & \multicolumn{3}{|c|}{ Moisture sinks in budget area } \\
\hline $\begin{array}{l}\text { Time period } \\
\text { (h) }\end{array}$ & \multicolumn{2}{|c|}{ Evaporation } & $\begin{array}{c}-\mathbf{v}_{h} \cdot \boldsymbol{\nabla} q \\
\text { advection }\end{array}$ & \multicolumn{2}{|c|}{$\begin{array}{c}-q\left(\boldsymbol{\nabla} \cdot \mathbf{v}_{h}\right) \\
\text { convergence }\end{array}$} & $\begin{array}{c}\partial w / \partial \mathrm{t} \\
\text { storage }\end{array}$ & \multicolumn{2}{|r|}{ Precipitation } \\
\hline $6-12$ & \multicolumn{2}{|l|}{54} & -2 & \multicolumn{2}{|c|}{48} & 63 & \multicolumn{2}{|r|}{37} \\
\hline $12-18$ & \multicolumn{2}{|l|}{49} & -14 & \multicolumn{2}{|c|}{65} & 27 & \multicolumn{2}{|r|}{73} \\
\hline $18-24$ & \multicolumn{2}{|l|}{48} & -17 & \multicolumn{2}{|c|}{69} & 8 & \multicolumn{2}{|r|}{92} \\
\hline $24-30$ & \multicolumn{2}{|l|}{52} & -27 & \multicolumn{2}{|c|}{75} & -12 & \multicolumn{2}{|r|}{112} \\
\hline
\end{tabular}


sitive to latent heat release and the surface evaporation from the underlying warm ocean. Errors in the model initial conditions, involving data interpolation between any analysis and model grid, tend to decay with time, and more rapidly so in "dry" simulations. Only the radiation in the surface energy budget contributes to the rms error growth in the lowest $2 \mathrm{~km}$, but it has a small impact on the deepening of the storm. However, the model fails to produce the secondary cyclogenesis in the absence of latent heating. It is shown that the surface evaporation is as instrumental as the latent heat release in the genesis. In particular, the simulated explosive deepening is sensitive to the timing of the surface evaporation during the life cycle of the storm. Water vapor budget calculations from the control experiment show that the surface moisture flux from 6 to $12 \mathrm{~h}$ is the largest contributor of water vapor to the budget area in the vicinity of the cyclone center, and remains an important contributor throughout the rest of the simulation. The surface moisture flux in the first 12 -h integration is crucial in inducing the grid-scale diabatic heating and destabilizing the lower troposphere, thereby assisting the preconditioning of the storm environment. A secondary maximum in surface latent heat flux (see Fig. 9), to the north and east of the primary maximum, seems to be crucial in forcing a cyclogenesis event to the south and east of the coastal center seen at 0600 UTC 7 March 1986 (see Fig. 2). Additional experiments involving a reduction in the initial water vapor content in a deep layer produce little impact upon the subsequent storm development, confirming the importance of the surface moisture flux aiding in the triggering of precipitation processes and the cyclogenesis.

In conclusion, we may state that the upper-level baroclinic waves and the low-level baroclinicity provide a favorable environment for the development of the IOP14 storm, whereas latent heat release determines whether or not the secondary cyclogenesis would take place. In particular, it is the ocean evaporation that generates the needed moisture content to trigger the grid- and subgrid-scale condensation and supply moist energy necessary for the subsequent latent heat release. This conclusion appears to differ from the typical large-scale extratropical cyclogenesis in which the upper-level baroclinic forcings tend to dominate (Lackmann et al. 1996).

These results suggest that the variability in COMPARE (i.e., cyclone intensity and 6-hourly positions) may result from the precipitation generation processes in the models that are responsible for the creation of the low-level PV maximum. Evidently, to improve the predictability of the track and intensity of this type of secondary cyclogenesis, operational models should include better physical parameterizations, including the condensation and boundary layer processes, in addition to obtaining more realistic initial conditions.

Acknowledgments. This work was based on the first author's (MLC) M.Sc. research. We wish to thank Dr. Gary Lackmann for helpful discussions, Mr. James Caveen and Dr. Clément Chouinard for helping with the processing of the COMPARE data, and Dr. Robert Benoit, Mr. Michel Desgagné, and Mr. Pierre Pellerin for their assistance in operating the MC2 model. The research was supported by the Natural Sciences and Engineering Research Council (NSERC) and the Atmospheric Environment Service. The first author was also supported by a postgraduate scholarship from NSERC and a contract from the Recherche en Prévision $\mathrm{Nu}-$ mérique. We appreciate the comments provided by two anonymous reviewers, which helped to improve the manuscript.

\section{APPENDIX A}

\section{Summary of the Mesoscale Compressible Community Model (MC2)}

\section{Numerics}

The following attributes apply to the model:

1) Fully compressible, nonhydrostatic, Euler equations (Tanguay et al. 1990);

2) semi-Lagrangian treatment of advection, semi-implicit scheme for time differencing;

$3)$ staggered grids in horizontal and vertical, modified Gal-Chen vertical coordinate $\zeta(X, Y, z)$,

$$
\zeta(X, Y, z)=\left[\frac{z-h_{o}(X, Y)}{H-h_{o}(X, Y)}\right] H,
$$

where $\zeta$ is the height in Gal-Chen units of length, $h_{\mathrm{o}}$ is a function representing topography, and $H$ is the model-top height.

\section{Physics}

The model incorporates the following:

1) Planetary boundary layer scheme based on predictive equation for turbulent kinetic energy (Benoit et al. 1989);

2) removal of excess moisture in supersaturated layers;

3) Kuo (Anthes 1977) convective parameterization scheme;

4) solar radiation accounting for $\mathrm{H}_{2} \mathrm{O}, \mathrm{CO}_{2}, \mathrm{O}_{3}$, and cloud effects (Fouquart and Bonnel 1980);

5) infrared radiation scheme incorporating cloud interaction and radiative effects of $\mathrm{CO}_{2}, \mathrm{O}_{3}, \mathrm{H}_{2} \mathrm{O}$, and clouds (Garand 1983);

6) surface fluxes calculated from Monin-Obukhov similarity theory for the surface layer: 
Sensible Heat Flux

$$
H_{s}=\rho_{a} c_{p}\left(\frac{T}{\theta}\right)_{a} \overline{\left(w^{\prime} \theta^{\prime}\right)_{s}}
$$

Vapor Flux

$$
\begin{aligned}
E_{s} & =\rho_{a} \overline{\overline{\left(w^{\prime} q^{\prime}\right)_{s}}} \\
\overline{\left(w^{\prime} \theta^{\prime}\right)_{s}} & =C_{M} C_{T}\left|V_{a}\right|\left(\theta_{s}-\theta_{a}\right), \\
\overline{\left(w^{\prime} q^{\prime}\right)_{s}} & =C_{M} C_{T}\left|V_{a}\right|\left(q_{s}-q_{a}\right),
\end{aligned}
$$

where $a=$ anemometer level; $s=$ surface level; $C_{T}$, $C_{M}$, heat and momentum transfer coefficients; $V_{a}$ wind modulus; $q=$ specific humidity; $\rho=$ density; $w=$ vertical motion; $T=$ temperature; and $\theta=$ potential temperature.

\section{Control integration parameters}

The following control integration parameters are incorporated in the model:

1) Polar stereographic projection $175 \times 153,50-\mathrm{km}$ resolution, time step of $600 \mathrm{~s}$;

2) $20 \mathrm{Gal}-\mathrm{Chen}$ levels in the vertical, model top of $30000 \mathrm{~m}$, no dynamic initialization.

\section{APPENDIX B}

\section{Generation of Interpolation Errors for Perturbed Integration (PER)}

Initial data: Polar stereographic projection, $50-\mathrm{km}$ resolution, 44 isobaric levels in the vertical.

- Step 1: Interpolate linearly in the horizontal to offset grid of equal $50-\mathrm{km}$ resolution and 44 levels in the vertical. The grid is offset $25 \mathrm{~km}$ in the east-west direction and $25 \mathrm{~km}$ in the north-south direction.

- Step 2: Vertically interpolate (in natural $\log p$ ) from 44 isobaric levels to 11 levels. The 11 isobaric levels are derived from the inclusion of the most elevated level of $10 \mathrm{hPa}$, and subsequently dividing the remaining $1040 \mathrm{hPa}$ into 10 equally spaced levels of $104 \mathrm{hPa}$ each. Hence the 11 isobaric levels are given by $10,114,218,322,426,530,634,738,842,946$, and $1050 \mathrm{hPa}$.

- Step 3: Interpolate linearly in the horizontal back to the original polar stereographic projection with the same $50-\mathrm{km}$ resolution.

- Step 4: Vertically interpolate (in natural $\log p$ ) back to the original 44 isobaric levels.

Note: The two-dimensional geophysical fields were perturbed by means of the described horizontal interpolation.

\section{REFERENCES}

Anthes, R. A., 1977: A cumulus parameterization scheme utilizing a one-dimensional cloud model. Mon. Wea. Rev., 105, 270-286.

- , Y.-H. Kuo, D. P. Baumhefner, R. M. Errico, and T. W. Bettge, 1985: Predictability of mesoscale atmospheric motions. Issues in atmospheric and oceanic modeling. Advances in Geophysics, Vol. 288, Academic Press, 159-202.

-,- , E.-Y. Hsie, S. Low-Nam, and T. Bettge, 1989: Estimation of skill and uncertainty in regional numerical models. Quart. J. Roy. Meteor. Soc., 115, 763-806.

Benoit, R., J. Côté, and J. Mailhot, 1989: Inclusion of a TKE boundary layer parameterization in the Canadian regional finite-element model. Mon. Wea. Rev., 117, 1726-1750.

Bosart, L. F., and F. Sanders, 1981: The Johnstown flood of July 1977: A long-lived convective system. J. Atmos. Sci., 38, 1616-1642.

, C. C. Lai, and E. Rogers, 1995: Incipient explosive marine cyclogenesis: Coastal development. Tellus, 47A, 1-29.

Chouinard, C., J. Mailhot, H. L. Mitchell, A. Staniforth, and R. Hogue, 1994: The Canadian regional data assimilation system: Operational and research applications. Mon. Wea. Rev., 122, 13061325.

Daley, R., 1981: Predictability experiments with a baroclinic model. Atmos.-Ocean, 19, 98-116.

Davis, C. A., and K. A. Emanuel, 1991: Potential vorticity diagnostics of cyclogenesis. Mon. Wea. Rev., 119, 1929-1953.

Dirks, R. A., J. P. Kuettner, and J. A. Moore, 1988: Genesis of Atlantic Lows Experiment (GALE): An overview. Bull. Amer. Meteor. Soc., 69, 148-160.

Errico, R. M., and D. P. Baumhefner, 1987: Predictability experiments using a high-resolution limited-area model. Mon. Wea. Rev., 115, 488-504.

Fouquart, Y., and B. Bonnel, 1980: Computations of solar heating of the earth's atmosphere: A new parameterization. Contrib. Atmos. Phys., 53, 35-62.

Fritsch, J. M., and C. F. Chappell, 1980: Numerical prediction of convectively driven mesoscale pressure systems. Part I: Convective parameterization. J. Atmos. Sci., 37, 1722-1733.

Garand, L., 1983: Some improvements and complements to the infrared emissivity algorithm including a parameterization of the absorption in the continuum region. J. Atmos. Sci., 40, 230-244.

Gyakum, J. R., and Coauthors, 1995: First COMPARE Workshop: 3-5 October 1994, Montreal, Quebec, Canada. Bull. Amer. Meteor. Soc., 76, 1209-1218.

_ - and Coauthors, 1996: A regional model intercomparison using a case of explosive oceanic cyclogenesis. Wea. Forecasting, 11, 521-543.

Hakim, G. J., L. F. Bosart, and D. Keyser, 1995: The Ohio Valley wave-merger cyclogenesis event of 25-26 January 1978. Part I: Multiscale case study. Mon. Wea. Rev., 123, 2663-2692.

Hoskins, B. J., M. E. McIntyre, and A. W. Robertson, 1985: On the use and significance of isentropic potential vorticity maps. Quart. J. Roy. Meteor. Soc., 111, 877-946.

Joly, A., and Coauthors, 1997: The Fronts and Atlantic Storm-Track Experiment (FASTEX): Scientific objectives and experimental design. Bull. Amer. Meteor. Soc., 78, 1917-1940.

Kuo, H. L., 1974: Further studies on the parameterization of the influence of cumulus convection on large-scale flow. J. Atmos. Sci., 31, 1232-1240.

Kuo, Y.-H., and R. A. Anthes, 1984: Mesoscale budgets of heat and moisture in a convective system over the central United States. Mon. Wea. Rev., 112, 1482-1497.

, and R. J. Reed, 1988: Numerical simulation of an explosively deepening cyclone in the eastern Pacific. Mon. Wea. Rev., 116, 2081-2105.

, _ _ , and S. Low-Nam, 1991: Effects of surface energy fluxes during the early development and rapid intensification stages of seven explosive cyclones in the western Atlantic. Mon. Wea. Rev., 119, 457-476.

— , J. R. Gyakum, and Z. Guo, 1995: A case of rapid continental mesoscale cyclogenesis. Part I: Model sensitivity experiments. Mon. Wea. Rev., 123, 970-997.

Lackmann, G. M., L. F. Bosart, and D. Keyser, 1996: Planetary- and synoptic-scale characteristics of explosive wintertime cyclogenesis over the western North Atlantic Ocean. Mon. Wea. Rev., 124, 2672-2702. 
Lapenta, W. M., and N. L. Seaman, 1992: A numerical investigation of East Coast cyclogenesis during the cold-air damming event of 27-28 February 1982. Part II: Importance of physical mechanisms. Mon. Wea. Rev., 120, 52-76.

Mailhot, J., 1994: The Regional Finite-Element (RFE) Model scientific description. Part 2: Physics. 42 pp. [Available from RPN 2121 Trans-Canada, Dorval, PQ H9P 1J3, Canada.]

— , and C. Chouinard, 1989: Numerical forecasts of explosive winter storms: Sensitivity experiments with a meso- $\alpha$ scale model. Mon. Wea. Rev., 117, 1311-1343.

Manabe, S., J. Smagorinsky, and R. F. Strickler, 1965: Simulated climatology of a general circulation model with a hydrologic cycle. Mon. Wea. Rev., 93, 769-798.

Miller, J. E., 1946: Cyclogenesis in the Atlantic coastal region of the United States. J. Meteor., 3, 31-44.

Mullen, S. L., and D. P. Baumhefner, 1988: The sensitivity of numerical simulations of explosive oceanic cyclogenesis to changes in physical parameterizations. Mon. Wea. Rev., 116, 2289-2329.

Reed, R. J., and A. J. Simmons, 1991: An explosively deepening cyclone over the North Atlantic that was unaffected by concurrent surface energy fluxes. Wea. Forecasting, 6, 117-122.

—, G. A. Grell, and Y.-H. Kuo, 1993: The ERICA IOP 5 storm. Part II: Sensitivity tests and further diagnosis based on model output. Mon. Wea. Rev., 121, 1595-1612.

Robert, A., T. L. Yeem, and H. Ritchie, 1985: A semi-Lagrangian and semi-implicit numerical integration scheme for multilevel atmospheric models. Mon. Wea. Rev., 113, 388-394.

Sanders, F., 1971: Analytic solutions of the nonlinear omega and vorticity equations for a structurally simple model of distur- bances in the baroclinic westerlies. Mon. Wea. Rev., 99, 393407.

Sasamori, T., 1972: A linear harmonic analysis of atmospheric motion with radiative dissipation. J. Meteor. Soc. Japan, 50, 505-518.

Snyder, C., 1996: Summary of an informal workshop on adaptive observations and FASTEX. Bull. Amer. Meteor. Soc., 77, 953961.

Stewart, R. E., R. W. Shaw, and G. A. Isaac, 1987: Canadian Atlantic Storms Program: The meteorological field project. Bull. Amer. Meteor. Soc., 68, 338-345.

Sundqvist, H., E. Berge, and J. E. Kristjansson, 1989: Condensation and cloud parameterization studies with a mesoscale numerical weather prediction model. Mon. Wea. Rev., 117, 1641-1657.

Tanguay, M., A. Robert, and R. Laprise, 1990: A semi-implicit semiLagrangian fully compressible regional forecast model. Mon. Wea. Rev., 118, 1970-1980.

Trenberth, K. E., and C. J. Guillemot, 1995: Evaluation of the global atmospheric moisture budget as seen from analyses. J. Climate, 8, 2255-2272.

Uccellini, L. W., 1990: Processes contributing to the rapid development of extratropical cyclones. Extratropical Cyclones: The Erik Palmén Memorial Volume, C. W. Newton and E. O. Holapainen, Eds., Amer. Meteor. Soc., 81-105.

Vukicevic, T., and R. M. Errico, 1990: The influence of artificial and physical factors upon predictability estimates using a complex limited-area model. Mon. Wea. Rev., 118, 1460-1482.

Yau, M. K., and M. Jean, 1989: Synoptic aspects and physical processes in the rapidly intensifying cyclone of 6-8 March 1986. Atmos.-Ocean, 27, 59-86. 